OPEN ACCESS

Edited by:

Jaewoo Hong,

Catholic University of Daegu,

South Korea

Reviewed by:

Seung Hyun Han,

Seoul National University, South Korea

Hee Sam Na,

Pusan National University,

South Korea

Mee-Hyun Lee,

Dongshin University, South Korea

*Correspondence:

Na-Young Song

nysong608@yuhs.ac

${ }^{\dagger}$ These authors have contributed equally to this work

Specialty section:

This article was submitted to

Cancer Immunity and Immunotherapy,

a section of the journal

Frontiers in Immunology

Received: 02 November 2021 Accepted: 26 November 2021 Published: 15 December 2021

Citation: Hwang B-O, Park S-Y, Cho ES, Zhang $X$, Lee SK, Ahn H-J, Chun K-S, Chung W-Y and Song N-Y (2021) Platelet CLEC2Podoplanin Axis as a Promising Target for Oral Cancer Treatment.

Front. Immunol. 12:807600. doi: 10.3389/fimmu.2021.807600

\section{Platelet CLEC2-Podoplanin Axis as a Promising Target for Oral Cancer Treatment}

\author{
Byeong-Oh Hwang ${ }^{1,2,3 \dagger}$, Se-Young Park ${ }^{1,2,3 \dagger}$, Eunae Sandra Cho ${ }^{2,4,5}$, Xianglan Zhang ${ }^{5,6}$, \\ Sun Kyoung Lee ${ }^{3}$, Hyung-Joon Ahn ${ }^{7}$, Kyung-Soo Chun ${ }^{8}$, Won-Yoon Chung ${ }^{1,2,3,5}$ \\ and Na-Young Song ${ }^{1,2,3^{*}}$ \\ ${ }^{1}$ Department of Applied Life Science, The Graduate School, Yonsei University, Seoul, South Korea, ${ }^{2}$ BK21 Four Project, \\ Yonsei University College of Dentistry, Seoul, South Korea, ${ }^{3}$ Department of Oral Biology, Yonsei University College of \\ Dentistry, Seoul, South Korea, ${ }^{4}$ Department of Oral Pathology, Yonsei University College of Dentistry, Seoul, South Korea, \\ ${ }^{5}$ Oral Cancer Research Institute, Yonsei University College of Dentistry, Seoul, South Korea, ${ }^{6}$ Department of Pathology, \\ Yanbian University Hospital, Yanji City, China, ${ }^{7}$ Department of Orofacial Pain and Oral Medicine, Dental Hospital, Yonsei \\ University College of Dentistry, Seoul, South Korea, ${ }^{8}$ College of Pharmacy, Keimyung University, Daegu, South Korea
}

Cancer tissues are not just simple masses of malignant cells, but rather complex and heterogeneous collections of cellular and even non-cellular components, such as endothelial cells, stromal cells, immune cells, and collagens, referred to as tumor microenvironment (TME). These multiple players in the TME develop dynamic interactions with each other, which determines the characteristics of the tumor. Platelets are the smallest cells in the bloodstream and primarily regulate blood coagulation and hemostasis. Notably, cancer patients often show thrombocytosis, a status of an increased platelet number in the bloodstream, as well as the platelet infiltration into the tumor stroma, which contributes to cancer promotion and progression. Thus, platelets function as one of the important stromal components in the TME, emerging as a promising chemotherapeutic target. However, the use of traditional antiplatelet agents, such as aspirin, has limitations mainly due to increased bleeding complications. This requires to implement new strategies to target platelets for anti-cancer effects. In oral squamous cell carcinoma (OSCC) patients, both high platelet counts and low tumorstromal ratio (high stroma) are strongly correlated with increased metastasis and poor prognosis. OSCC tends to invade adjacent tissues and bones and spread to the lymph nodes for distant metastasis, which is a huge hurdle for OSCC treatment in spite of relatively easy access for visual examination of precancerous lesions in the oral cavity. Therefore, locoregional control of the primary tumor is crucial for OSCC treatment. Similar to thrombocytosis, higher expression of podoplanin (PDPN) has been suggested as a predictive marker for higher frequency of lymph node metastasis of OSCC. Cumulative evidence supports that platelets can directly interact with PDPN-expressing cancer cells via C-type lectin-like receptor 2 (CLEC2), contributing to cancer cell invasion and metastasis. Thus, the platelet CLEC2-PDPN axis could be a pinpoint target to inhibit interaction between platelets and OSCC, avoiding undesirable side effects. Here, we will 
review the role of platelets in cancer, particularly focusing on CLEC2-PDPN interaction, and will assess their potentials as therapeutic targets for OSCC treatment.

Keywords: platelets, tumor cell-induced platelet aggregation (TCIPA), CLEC2, PDPN, ezrin/radixin/moesin (ERM), oral cancer

\section{INTRODUCTION}

Oral squamous cell carcinoma (OSCC) is the most prevalent type of head and neck malignancies that occur in oral cavity, salivary gland, pharynx, larynx, nasal cavity, thyroid, and bone (1). Unlike the other types of cancers, OSCC usually arises from the body part that is easily accessible for visual examinations. Despite this advantage in detection of precancerous lesions, most of the OSCC patients are not diagnosed until the advanced stages with metastasis, which is attributed to low overall survival rates (2). Oral mucosa contains a connective tissue enriched with type I collagen that is synthesized by stromal cells (3). Desmoplasia, a status of the excessive growth of the stromal tissue, is closely associated with $\operatorname{OSCC}(4,5)$. In OSCC patients, stroma-rich tumors are more aggressive and metastatic than stroma-poor tumors, finally contributing to the poor survival rates $(6,7)$. The activated tumor stroma can supply a variety of growth factors and cytokines that induces cancer cell proliferation as well as extracellular matrix (ECM) remodeling $(5,8)$. In support of the tumor stroma, OSCC cells tend to invade adjacent tissues, such as bones, and spread to the lymph nodes (9). This locoregional characteristic of OSCC is the primary cause of treatment failure (10). Thus, how to control the local and distal metastasis is crucial for successful treatment and better prognosis in OSCC patients.

Platelets, the smallest cells in blood circulation, play a major role in blood coagulation and hemostasis (11-13). In addition to their primary physiological functions, platelets are profoundly involved in cancer promotion and progression $(14,15)$. Recently, it has been reported that platelets can infiltrate into the tumor stroma in colorectal and pancreatic cancer patients (16-18). As a part of the tumor stromal components, platelets crosstalk with cancer cells either directly or indirectly, promoting invasion and metastasis (19-21). For the physical interaction, C-type lectinlike receptor 2 (CLEC2) and podoplanin (PDPN) are suggested as the key molecular links expressed in platelets and tumors, respectively (22). Moreover, cancer cells activate and educate platelets, thus the bilateral interaction between platelets and cancer can further promote tumorigenesis, creating a positive feedback loop (23). Notably, OSCC patients often show increased platelet counts, which is strongly associated with poor prognosis $(24,25)$. Thus, platelets are emerging as an important target for chemotherapy in OSCC patients.

Aspirin, a representative antiplatelet agent, is well known to protect against carcinogenesis (26-28). Aspirin irreversibly inhibits both cyclooxygenase-1 (COX-1) and COX-2, reducing synthesis of prostaglandins and thromboxanes responsible for inflammation and platelet aggregation (27). Despite its chemopreventive effect, a daily use of low-dose aspirin frequently causes adverse complications, primarily increased bleeding risk $(29,30)$. Thus, instead of using traditional antiplatelet agents, the pinpoint targeting of the platelet-tumor cell interaction would be a more precise and effective strategy for OSCC treatment, avoiding undesirable harmful effects. In this regards, we will highlight the role of platelets in carcinogenesis and OSCC, particularly focusing on the physical interaction between platelets and tumors via the CLEC2-PDPN axis.

\section{ROLES OF PLATELETS IN CANCER}

\section{Thrombocytosis in Cancer Patients}

Platelets are anucleated cells originated from megakaryocytes in the bone marrow and abundant in healthy individual $150,000 \sim 400,000$ per microliter of blood (11-13). In spite of lack of genomic DNA, platelets release plenty of granular ingredients, such as platelet-derived growth factor (PDGF), transforming growth factor $\beta$ (TGF $\beta$ ), stromal cell-derived factor-1 (SDF-1), and serotonin, which contributes to signal transduction in nearby cells (31). Cancer is often associated with thrombocytosis, a status of an abnormal elevation of platelet counts, which shows a positive correlation with worse outcomes in many types of cancers $(24,32-34)$. High platelet counts are involved with development of venous thromboembolism (VTE) in cancer patients, the second leading cause of cancer death (3538). Besides an increased risk of VTE, thrombocytosis is associated with cancer mortality by accelerating tumor promotion and progression as well (39-41). In mice bearing tumors, platelet transfusion induced the blood platelet counts as well as tumor growth, while reducing the survival rates $(37,42)$. Thus, the platelet counts have long been considered as a valuable prognostic marker in cancer patients.

It has been reported that inflammatory cytokines, such as interleukin-6 (IL-6), are highly associated with thrombocytosis in cancer patients $(33,43)$. IL-6 can stimulate platelet production through inducing thrombopoietin $(33,44)$. In murine colitis model, colitis-induced wild type (WT) mice showed thrombocytosis and platelet aggregation, which were absent in IL-6-deficient mice (45). Moreover, neutralization of IL-6 led to reduction of platelet counts and tumor growth in the mouse ovarian cancer model (33). Thus, IL-6 inhibitors might be utilized to mitigate cancer-associated thrombocytosis (46). However, anti-IL-6 treatments need meticulous assessment, regarding that IL-6 pleiotropically functions in immune system $(47,48)$.

\section{Platelets as a Part of Stromal Components in Tumor Microenvironment}

Tumor tissues are not just simple masses of malignant cells, but rather complex and heterogeneous collections of cellular and 
even non-cellular components, referred to as tumor microenvironment (TME) (49). The multiple players in the TME develop dynamic interactions with each other, which determines the characteristics of the tumor (50). The noncellular parts of the TME comprise primarily the ECM, a three-dimensional scaffold that contains collagens, proteoglycans, and fibronectins (51). The acellular ECM is crucial for providing mechanical (structural) and biochemical (nutritional) supports to cellular components in the TME (52). The cellular players in the TME can be largely divided into stromal cells and tumor-infiltrating immune cells. The tumor stroma is a heterogeneous population of distinct types of cells, including fibroblasts and endothelial cells (53). Among them, cancer-associated fibroblasts (CAFs) are the most abundant type of the stromal cells in TME that display enhanced expression of the signature proteins, including $\alpha$-smooth muscle actin and PDGF receptors (54). Moreover, the TME contains a broad spectrum of immune cells, such as tumor-associated macrophages, tumor-associated neutrophils, and regulatory $\mathrm{T}$ cells. Notably, the infiltration of platelets into the tumor stroma has been observed in cancer patients $(18,55,56)$, along with increased blood platelet counts $(24,32-34)$. Tumor-infiltrating platelets can interact with other stromal players of TME, contributing to tumor promotion and progression (57). Miyashita et al. have found that CAFs were surrounded by platelets in almost half of the pancreatic cancer patients (58). Platelet-derived factors, like TGF $\beta$, PDGF, and SDF-1, can stimulate recruitment and activation of CAFs in the TME (5962). Platelets also accommodate various angiogenesis regulators, which can turn on local angiogenesis in the TME (63). Depletion of tumor-infiltrating platelets showed impaired tumor blood vessel structures in mice (64). Moreover, it has been reported that fusion between platelets and endothelial cells promotes cancer metastasis by facilitating adhesion of tumor and endothelial cells (65). In consistent, the intratumoral accumulation of platelets are related to tumor progression (18, $55,56)$. These investigations support that platelets function as a crucial stromal component in the TME through vigorous interplay with other members.

\section{Platelets in Cancer Invasion and Metastasis}

Metastasis is a multi-step process, including local invasion, intravasation, and colonization at the distal sites (66). Invading cancer cells undergo dramatic alterations in their morphology and phenotypes, such as epithelial-to-mesenchymal transition (EMT), which is accompanied by remodeling of the ECM (66). As a poor prognostic indicator, thrombocytosis is associated with lymph node metastasis and invasion in cancer patients $(24,67)$. In consistent, platelet transfusion significantly enhanced metastasis of cancer cells in the murine experimental models $(15,68)$. However, platelet decoys bound to tumor cells as effectively as normal intact platelets and inhibited thrombosis and metastatic tumor formation, further supporting the role of platelets in metastasis (69). Of note, platelets are frequently detected at the invasive front where both EMT and ECM remodeling occur actively (70). Platelets contain about $40 \%$ of
TGF $\beta$ found in the peripheral blood plasma, which plays a crucial role in cancer cell invasion (71). Co-culture with platelets remarkably enhanced invasiveness and EMT process of cancer cells in a TGF $\beta$-dependent manner $(72,73)$. Plateletspecific Tgfb1-deficient mice showed reduction in tumor growth and platelet extravasation, compared to WT mice (74). Moreover, various types of matrix metalloproteinases (MMPs) responsible for ECM degradation are stored in the resting platelets and released upon stimulation, such as cancer cellinduced aggregation $(35,75,76)$. Platelets upregulate production of MMPs in cancer cells as well as fibroblasts, accelerating invasion of cancer cells (77-79). These data suggest that platelets can change TME through their releasates, such as TGF $\beta$ and MMPs, conferring cancer cells invasive capability and metastatic potential. In addition, direct contact with platelets can promote invasion and metastasis of cancer cells in vitro and in vivo $(19,80)$.

Platelets can promote metastasis through interaction with other cells in the bloodstream as well, like in the TME. Platelets rapidly adhere to circulating cancer cells in the blood, protecting tumors from immune surveillance $(41,81)$. Natural killer (NK) and CD8 T cells are cytotoxic lymphocytes that play a central role in cancer immunosurveillance (82). Once tumors are coated by platelets, platelets inhibit NK cell-mediated antitumor activity through downregulating tumor cell NK2D expression by TGF $\beta$ and inducing pseudoexpression of immunomodulating molecules, such as MHC I and GITR (83-85). Moreover, platelet-derived factors, such as TGF $\beta$ and programmed deathligand 1 (PD-L1), suppressed the cytotoxic antitumor $\mathrm{T}$ cell immunity in the mouse cancer models (86-88). Taken together, these data suggest that platelets facilitate tumor immune escape by surrounding cancer cells in the bloodstream, thus, the platelet-camouflaged cancer cells safely migrate to the metastatic sites. Of note, co-incubation with platelets protected cancer cells against anoikis, implying that platelets enhance anchorage-independent survival of circulating tumor cells in the bloodstream (15).

\section{Platelets as a Potential Target for OSCC Treatment}

Similar to other types of cancer patients, increased platelet counts are significantly correlated with poor prognosis in OSCC patients $(25,89)$. Based on the analysis of relationship between platelet counts and disease progression in a total of 253 OSCC patients, thrombocytosis was associated with lymph node metastasis as well as distant metastasis (90). Along with metastasis, advanced OSCC often shows invasion into the facial bones, due to close anatomical relationship (91, 92). The bone invasion causes severe pains, greatly lowering the quality of life and the survival rates in OSCC patients $(91,93)$. Notably, platelet aggregation plays a critical role in tumor-associated bone destruction (94). In line with that, the pharmacological inhibition of platelet aggregation reduced bone metastasis in the murine cancer model (95). Platelet-secreted lysophosphatidic acid is thought to be one of the primary mediators in plateletpromoted bone invasion and metastasis $(96,97)$. Taken together, platelets can facilitate bone invasion through direct contact with 
tumor as well as their releasates. In OSCC, bone destruction and invasion are closely related to $\operatorname{TGF} \beta$ signaling pathway $(98,99)$. Considering that platelets store most of the plasma TGF $\beta$, it is plausible that platelets aggravate invasion of OSCC, and thus further pre-clinical and clinical investigations will shed light on a noble would be novel strategies for OSCC treatment.

\section{INTERACTION BETWEEN PLATELETS AND CANCER: CLEC2-PDPN-ERM AXIS}

\section{PDPN in Cancer and Platelet Aggregation}

PDPN is a type I transmembrane glycoprotein expressed in kidney podocytes, skeletal muscles, lungs, hearts, myofibroblasts, osteoblasts, mesothelial cells, and lymphatic endothelial cells (100). PDPN knockout mice die shortly after birth due to an impaired respiratory system (101). These mice also show defects in the lymphatic vasculature, disorganization of spleen, and lack of lymph nodes $(102,103)$. PDPN is thus an important regulator in the normal organogenesis and development processes.

Upregulation of PDPN has been observed in a variety of human cancers, including brain cancer, breast cancer, lung cancer, and mesothelioma, which is associated with poor prognosis (104-107). In athymic nude mice, injection of PDPN-overexpressing cancer cells generated bigger tumors, while silencing of PDPN suppressed tumor growth (108). Moreover, PDPN-high tumors exhibited increased peritumoral lymphangiogenesis, invasiveness, migratory ability, and metastasis, implying a pro-tumorigenic role of PDPN (109112). Notably, it has been reported that PDPN expression is elevated at the leading edge of tumor tissues, which promotes cell surface extension and cell motility in keratinocytes $(111,113)$. In the two-stage skin carcinogenesis model, epidermal ablation of PDPN reduced tumor growth and invasion (109). Overall, these data suggest that PDPN confers cancer cells survival benefits, promoting tumor growth, invasion, and metastasis.

Interestingly, PDPN-overexpressing cancer cells evoke platelet aggregation, also known as tumor cell-induced platelet aggregation (TCIPA) $(108,114)$. PDPN-positive human glioblastoma Gli16 cells were able to markedly induce platelet aggregation, whereas not detected by PDPN-negative cells (115). In tumor-bearing mouse models, either ablating $P D P N$ gene or blocking PDPN by monoclonal antibody ( $\mathrm{mAb}$ ) injection effectively suppressed platelet aggregation, supporting that PDPN is crucial for TCIPA formation $(116,117)$. The PDPNmediated TCIPA was strongly associated with an increased incidence of VTE in cancer patients $(115,118)$. Moreover, PDPN overexpression is also involved in TCIPA-induced tumor promotion and progression. The platelet-tumor aggregates are readily arrested in the microvasculature, facilitating tumor metastasis (20). PDPN neutralization significantly inhibited TCIPA occurrence, tumor growth, and metastasis in nude mice injected with human melanoma or lung cancer cell lines $(108,116,119)$. Moreover, platelet-derived TGF $\beta$ upregulated PDPN expression in human bladder cancer cells, which induced EMT process and cancer cell invasion (120).
Taken together, PDPN is considered as a 'pinpoint' that interconnects between tumor and platelets, regulating VTE as well as tumor progression.

\section{Platelet CLEC2-PDPN Axis: A Pinpoint of Platelet-Tumor Cell Interaction}

PDPN consists of an extracellular domain, a transmembrane domain, and a cytoplasmic domain (121). The extracellular domain of PDPN carries four platelet aggregation-stimulating (PLAG) domains with a plenty of potential O-glycosylation sites, crucial for interaction with platelets (121). The PLAG domain of PDPN has been reported to bind to CLEC2 that is abundantly expressed on the surface of platelets (122). Interestingly, CLEC2deficient mice phenocopy PDPN-knockout mice, like prenatal lethality and impaired lymphatic vasculature (123). Either platelet-specific deletion of CLEC2 or inhibition of PDPN was associated with reduced thrombosis in a murine deep vein thrombosis model of inferior vena cava stenosis (124). Similarly, cancer cell lines with high endogenous PDPN expression levels, such as LN319 and Colon-26, showed induced platelet aggregation, which was attenuated by preincubation with an anti-CLEC2 antibody (125). Tsukiji et al. have found that cobalt hematoporphyrin $(\mathrm{Co}-\mathrm{HP})$ directly binds to PDPN-binding sites of CLEC2, functioning as an inhibitor of the CLEC2-PDPN axis (126). Both Co-HP administration and CLEC2 neutralization significantly inhibited CLEC2-dependent platelet aggregation in tumor-bearing mice $(126,127)$. Taken together, these data support that PDPN is interdependent with CLEC2, thus, the platelet CLEC2-PDPN axis is crucial for platelet-tumor cell interaction (Figure 1).

In conjunction with TCIPA formation, the platelet CLEC2PDPN axis mediates cancer promotion and progression. In mice inoculated with PDPN-expressing B16F10 melanoma cells, CLEC2 depletion by anti-CLEC2 $\mathrm{mAb} 2 \mathrm{~A} 2 \mathrm{~B} 10$ injection reduced plasma levels of inflammatory cytokines and lung metastasis, resulting in prolonged survival compared to control mice (127). Treatment with a CLEC2 inhibitor Co-HP suppressed lung metastasis of PDPNexpressing melanoma cells, but not that of PDPN-negative lung cancer cells (126). In platelet-depleted mice, platelet transfusion induced much more lung colonization as well as bone metastasis of PDPN-expressing osteosarcoma cells, while CLEC2 mAb injection reduced lung colonization (68). Likewise, injection of PDPN mAb (MS-1) remarkably suppressed platelet aggregation as well as lung metastasis in the murine cancer metastasis model (128). Therefore, the platelet CLEC2-PDPN axis is considered as a pinpoint for platelet-tumor interaction that promotes tumor progression (Figure 1). It has been demonstrated that CLEC2 deficiency is not significantly related to bleeding tendency $(123,129)$. In this regard, the platelet CLEC2-PDPN axis could be a promising target to inhibit TCIPA-induced tumor progression without bleeding risk, a major complication of the traditional antiplatelet agents.

\section{PDPN-ERM Axis: An Executor in Cancer Progression}

PDPN has a short cytoplasmic tail associated with ezrin/radixin/ moesin (ERM) proteins that primarily bridge between plasma 


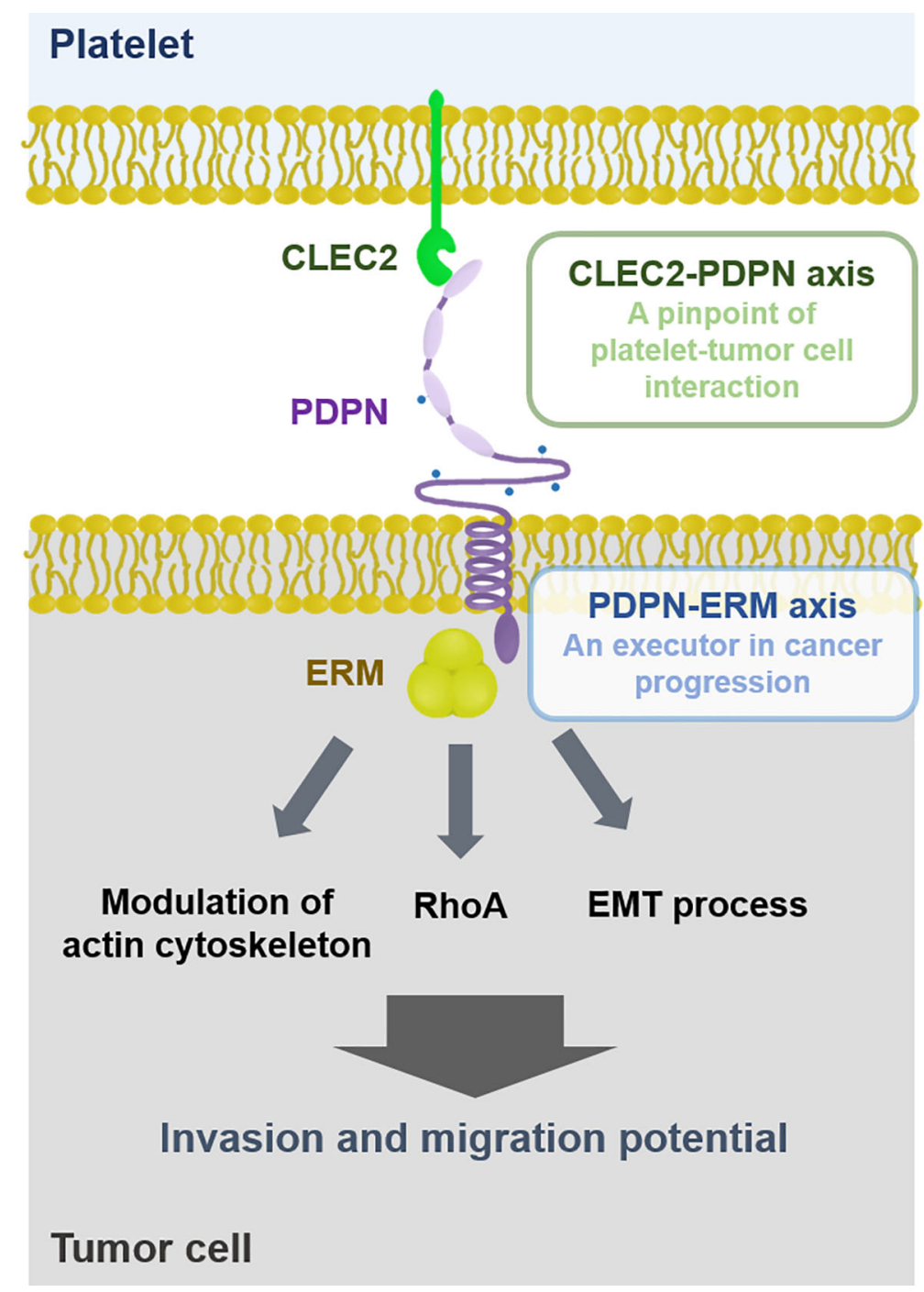

FIGURE 1 | Interaction between platelet and tumor cell. Platelets can physically interact with tumor cells via the CLEC2-PDPN axis. PDPN is associated with ERM proteins that promote cancer cell migration and invasion through modulating actin cytoskeleton, RhoA, and EMT process. Thus, the CLEC2-PDPN-ERM axis is a crucial target for chemotherapy.

membrane proteins and F-actin filaments of the cytoskeleton $(100,130)$. It is well documented that cells and tissues utilize this ERM crosslink system to maintain the architectures necessary for their own biological functions (131). In particular, ERM proteins are crucial regulators for epithelial morphogenesis and integrity, mitosis, cell polarity, and cell adhesion $(132,133)$. Among the ERM protein members, ezrin-null mice displayed much more severe phenotypes compared to moesin- or radixin-deficient mice (134). Ezrin-deficient mice showed defects in intestinal villus morphogenesis and epithelial cell organization (135). In addition, ERM proteins regulate the cell-cell and cell-matrix interactions, particularly in cancer cells (136). Thus, PDPN is engaged in cell adhesion, migration, and invasion through association with the ERM proteins, as illustrated in Figure 1 $(113,133)$.
PDPN expression is upregulated peculiarly in the growing edge of tumors and commonly co-localized with ERM proteins $(100,106)$. Similar to PDPN, overexpression of ERM proteins has been detected in various types of cancers: ezrin overexpression in breast, hepatocellular, colon, ovarian, and pancreatic cancers (137-141); radixin overexpression in pancreatic cancer with lymph node metastasis (142); moesin overexpression in skin cancer, colorectal carcinoma, endometrial adenocarcinoma, and glioma (143-146). Moreover, upregulation of ERM proteins is associated with poor prognosis in cancer patients (140, 147-150). In athymic nude mice, intracranial injection of moesin-overexpressing glioblastoma cells significantly reduced the survival rates compared to the control group (146). Moreover, ERM proteins were frequently mislocalized during tumor progression, from plasma 
membrane to cytoplasm (136). Thus, dysregulation of ERM proteins takes part in cancer promotion and progression, possibly in an interdependent manner with PDPN.

It has been reported that PDPN mediated TCIPA-induced EMT process in human cancer cell lines (120). In non-cancerous experimental settings, PDPN can bind to ERM proteins through its cytoplasmic domain, promoting the EMT process as well as cell migration $(130,151)$. Silencing of radixin, one of the ERM protein members, suppressed the EMT process as well as migration and invasion in human gastric carcinoma SGC-7901 cells (152). Moreover, PDPN can induce migration ability in cancer cells that bypass the EMT process via filopodia formation (106). Instead of the EMT process, PDPN recruits ERM proteins to modulate the actin cytoskeleton in a RhoA-dependent manner, consequently promoting cancer cell migration and invasion. Taken together, the PDPN-ERM axis can promote migratory capability and invasiveness of tumor cells, through either EMT process or cytoskeletal rearrangement.

It has been reported that the CLEC2-PDPN axis can regulate cell contractility and migration through activation of ERM proteins in non-cancerous settings (153-155). In this regard, it is plausible that the PDPN-ERM axis could be recruited by tumors bound to platelets via CLEC2-PDPN interaction, conferring cancer cells metastatic potentials (Figure 1). Further investigation is necessary to clarify the role of the platelet CLEC2-PDPN-ERM axis in cancer progression.

\section{Platelet CLEC2-PDPN and PDPN-ERM Axes in OSCC}

According to the Cancer Genome Atlas analysis, head and neck cancer patients present much higher PDPN expression levels compared to other types of cancer patients. While PDPN expression is rarely detected in normal oral epithelial cells, OSCC patients show upregulation of PDPN in tumors, which contributed to poor prognosis (156-159). In the xenograft mouse model, PDPN-overexpressing OSCC cells promoted tumor growth and intratumoral platelet accumulation, implying that PDPN mediates TCIPA formation in OSCC (160). Similar to high platelet counts (90), elevated PDPN expression was often found at the invasive front and correlated with lymph node metastasis in OSCC patients $(156,161)$. In line with that, silencing of PDPN gene expression attenuated migration and invasion in human OSCC cell lines (160, 162-164). Considering that platelet CLEC2 is crucial for PDPN-dependent TCIPA formation, the platelet CLEC2-PDPN axis would be a feasible target for successful local control in OSCC patients.

In OSCC patients, overexpression of ezrin and moesin has been detected in advanced staged tumors and significantly associated with worse overall survival rates (149, 164, 165). Kobayashi et al. have reported that cytoplasmic expression of moesin shows a strong correlation with lymph node metastasis in OSCC patients (166). Of note, PDPN expression was positively related to ezrin expression, particularly in the cytoplasm of the odontogenic tumors (167). Moreover, this co-expression between PDPN and ezrin was frequently detected in the invasive front and possibly involved with lymph node metastasis in the lip cancer (168). These data suggest that the PDPN-ERM axis may contribute to increased metastatic potential in OSCC. In consistent, PDPN has been reported to enhance cell motility and invasiveness through interaction with ERM binding partners, such as membrane type 1 MMP, Cdc42, and CD44, in humans OSCC cell lines $(162,164)$. These data suggest that ERM proteins function as an intracellular executor of the CLEC2-PDPN axis in invasion and metastasis of OSCC.

\section{TARGETING PLATELET-TUMOR INTERACTION FOR CHEMOTHERAPY}

\section{Aspirin}

Considering pro-tumorigenic activities of platelets, antiplatelet agents could be promising chemotherapeutics, as shown in Table 1. A classical antithrombotic drug aspirin has been used for chemoprevention. The meta-analysis and retrospective cohort study showed that a regular use of aspirin is associated with reduced risk of cancers in liver, stomach, colorectum, lung, pancreas, and oesophagus $(26,169)$. In head and neck cancer patients, evaluation of aspirin as a chemopreventive agent is still controversial. A hospital-based case control study revealed that aspirin use can reduce head and neck cancer risk (170), whereas the other investigations demonstrated that there was no significant correlation between aspirin intake and head and neck cancer $(171,172)$. Moreover, the risk of gastrointestinal bleeding could limit the use of aspirin for cancer prevention and/ or treatment $(29,30)$.

\section{Platelet P2Y12 Receptor Antagonists}

Platelet P2Y12 receptor is involved in ADP-stimulated activation of glycoprotein IIb/IIIa (GPIIb/IIIa) responsible for platelet aggregation (197). It has been reported that GPIIb/IIIa mediates platelet-tumor interaction and cancer metastasis (198-200). In conjunction with GPIIb/IIIa, stimulation of P2Y12 receptor can promote platelet-tumor crosstalk and cancer metastasis (Figure 2), suggesting P2Y12 receptor antagonists as anticancer drugs $(73,201)$. Clopidogrel, the most widely used P2Y12 receptor antagonist, markedly inhibited tumor growth in mouse ovarian and liver cancer models $(176,177)$. Another P2Y12 inhibitor ticagrelor suppressed proliferation of ovarian cancer cells in vivo and in vitro, which was not detected in absence of platelets (176). Moreover, treatment with ticagrelor attenuated TCIPA formation and cancer metastasis in the murine experimental models (178-180). These pre-clinical data suggest platelet P2Y12 receptor as a target for cancer treatment by controlling platelettumor aggregation. However, a population-based cohort study showed that the use of clopidogrel has no huge impact on cancer mortality in colorectal, breast, and prostate cancer patients (181). Even worse, the clinical trial-based analyses revealed that ticagrelor increased cancer risks $(183,184)$. In another patientlevel meta-analysis of randomized clinical trials, a long-term intake of clopidogrel was associated with bleeding risk and hemorrhage (182). Overall, the use of P2Y12 receptor antagonists for 
TABLE 1 | Strategies to target platelet-tumor interaction for chemotherapy.

\begin{tabular}{|c|c|c|c|c|}
\hline Agent & TCIPA & Cancer risk/metastasis & Bleeding & References \\
\hline \multicolumn{5}{|l|}{ Classical antiplatelet drug } \\
\hline Aspirin & $\begin{array}{l}\text { Inhibit TCIPA in vitro and in } \\
\text { vivo }\end{array}$ & $\begin{array}{l}\text { Inhibit metastasis in vivo } \\
\text { Cancer preventive effect in human subjects } \\
\text { (controversial in head and neck cancer) } \\
\text { Reduce metastasis in cancer patients }\end{array}$ & Increased gastrointestinal bleeding & $\begin{array}{l}(26,29,30 \\
169-175)\end{array}$ \\
\hline \multicolumn{5}{|l|}{ P2Y12 receptor antagonism } \\
\hline Clopidogrel & Inhibit TCIPA in mice & $\begin{array}{l}\text { Inhibit tumor metastasis in mice } \\
\text { No impact on cancer motility in human } \\
\text { colorectal, breast, and prostate cancer } \\
\text { patients }\end{array}$ & $\begin{array}{l}\text { A long-term use can increase } \\
\text { bleeding risk }\end{array}$ & $(176-182)$ \\
\hline Ticagrelor & Inhibit TCIPA & Increase cancer risks in human & $\begin{array}{l}\text { More major bleeding compared to } \\
\text { clopidogrel in patients with acute } \\
\text { coronary syndrome }\end{array}$ & $(180,183-185)$ \\
\hline \multicolumn{5}{|l|}{ GPVI antagonism } \\
\hline Anti-GPVI mAb (JAQ1) & Inhibit TCIPA & $\begin{array}{l}\text { Inhibit cancer cell extravasation in vitro } \\
\text { Inhibit metastasis in mice } \\
\text { Induce intratumoral hemorrhage and } \\
\text { accumulation of co-administrated } \\
\text { anticancer drugs in mice }\end{array}$ & No impact on bleeding time & $(129,186-188)$ \\
\hline Revacept & $\begin{array}{l}\text { Inhibit TCIPA in mice and } \\
\text { human }\end{array}$ & Inhibit EMT marker expression in vitro & $\begin{array}{l}\text { No impact on bleeding time in mice } \\
\text { and human }\end{array}$ & $(189-191)$ \\
\hline \multicolumn{5}{|l|}{ Targeting CLEC2-PDPN axis } \\
\hline $\begin{array}{l}\text { Anti-CLEC2 mAb (2A2B10 and } \\
\text { INU1) }\end{array}$ & $\begin{array}{l}\text { Inhibit intratumoral thrombus } \\
\text { formation in mice }\end{array}$ & Inhibit metastasis in mice & No impact on bleeding time & $(68,127,129)$ \\
\hline $\begin{array}{l}\text { Anti-PDPN mAb (NZ-1, MS-1, } \\
\text { and SZ-168) }\end{array}$ & $\begin{array}{l}\text { Inhibit platelet aggregation in } \\
\text { mice }\end{array}$ & $\begin{array}{l}\text { Inhibit metastasis in mice } \\
\text { Inhibit VET in mice }\end{array}$ & & $\begin{array}{c}(119,128,192- \\
194)\end{array}$ \\
\hline $2 \mathrm{CP}$ & Inhibit TCIPA in mice & Inhibit metastasis in mice & No impact on bleeding time & $(195)$ \\
\hline Co-HP & Inhibit platelet aggregation & $\begin{array}{l}\text { Inhibit metastasis in mice } \\
\text { Inhibit VET in mice }\end{array}$ & No impact on bleeding time & $(126)$ \\
\hline $\begin{array}{l}\text { Polysaccharide extracted from } \\
\text { Artemisia argyi leaves }\end{array}$ & Inhibit TCIPA & & & $(196)$ \\
\hline
\end{tabular}

chemotherapy is controversial, in spite of the compelling preclinical evidence.

\section{Platelet GPVI Antagonism}

GPVI is the major platelet-activating receptor exclusively expressed on platelets and megakaryocytes (202). GPVI-null mice showed lack of thrombus formation and defective platelet activation without severe bleeding tendency (203, 204). Moreover, these GPVI-deficient mice developed less metastatic tumors by injection of lung cancer or melanoma cells than WT mice (205). Notably, platelet GPVI can bind to galectin-3 on tumor cells, provoking platelet-tumor cell interaction and metastasis (Figure 2) (186, 189). These pre-clinical data suggest that GPVI antagonism is a conceivable strategy to block TCIPA-mediated tumor progression without adverse effects. In line with this notion, platelets preincubated with an anti-GPVI antibody (JAQ1) were less able to form aggregates with human breast cancer cells and eventually reduced cancer cell extravasation in the transendothelial migration assay (187). Moreover, treatment with JAQ1 reduced tumor metastasis in the murine lung metastasis models, further supporting antitumor effects of GPVI antagonism via blocking TCIPA formation (186). Interestingly, JAQ1 Fab2 fragment induced intratumoral hemorrhage that led to accumulation of co-administrated chemotherapeutics without systemic bleeding complications, thus allowing to maximize anticancer effects (188). Revacept, a competitive GPVI inhibitor comprising a soluble Fc fusion protein, decreased platelet-tumor interaction and metastatic potential in vitro (189). In atherosclerotic mice and healthy human subjects, Revacept reduced platelet aggregation with no impact on bleeding times $(190,191)$. Based on this drug safety assurance, the antitumor efficacy of GPVI antagonists must be further evaluated in human cancer patients.

\section{Targeting Platelet CLEC2-PDPN Axis}

As described in Figure 1, the platelet CLEC2-PDPN axis is emerging as a pinpoint to control the platelet-tumor interaction and subsequent tumor progression. In order to disconnect the platelet CLEC2-PDPN axis, diverse approaches have been made, including $\mathrm{mAbs}$ against CLEC2 or PDPN and pharmacological inhibitors. PDPN mAbs, such as NZ-1 and MS-1, can bind to the PLAG domain of PDPN and neutralize interaction with platelet CLEC2 (Figure 2) (192, 193). These PDPN mAbs specifically inhibited PDPN-mediated platelet aggregation and cancer metastasis in the murine experimental models $(128,192,193)$. Moreover, anti-PDPN antibody SZ-168 reduced the incidence of VTE in mice (194). Similar to PDPN mAbs, antiCLEC2 antibody 2A2B10 suppressed intratumoral thrombus formation as well as metastasis in mice $(68,127)$. These investigations suggest that mAbs neutralizing either CLEC2 or 


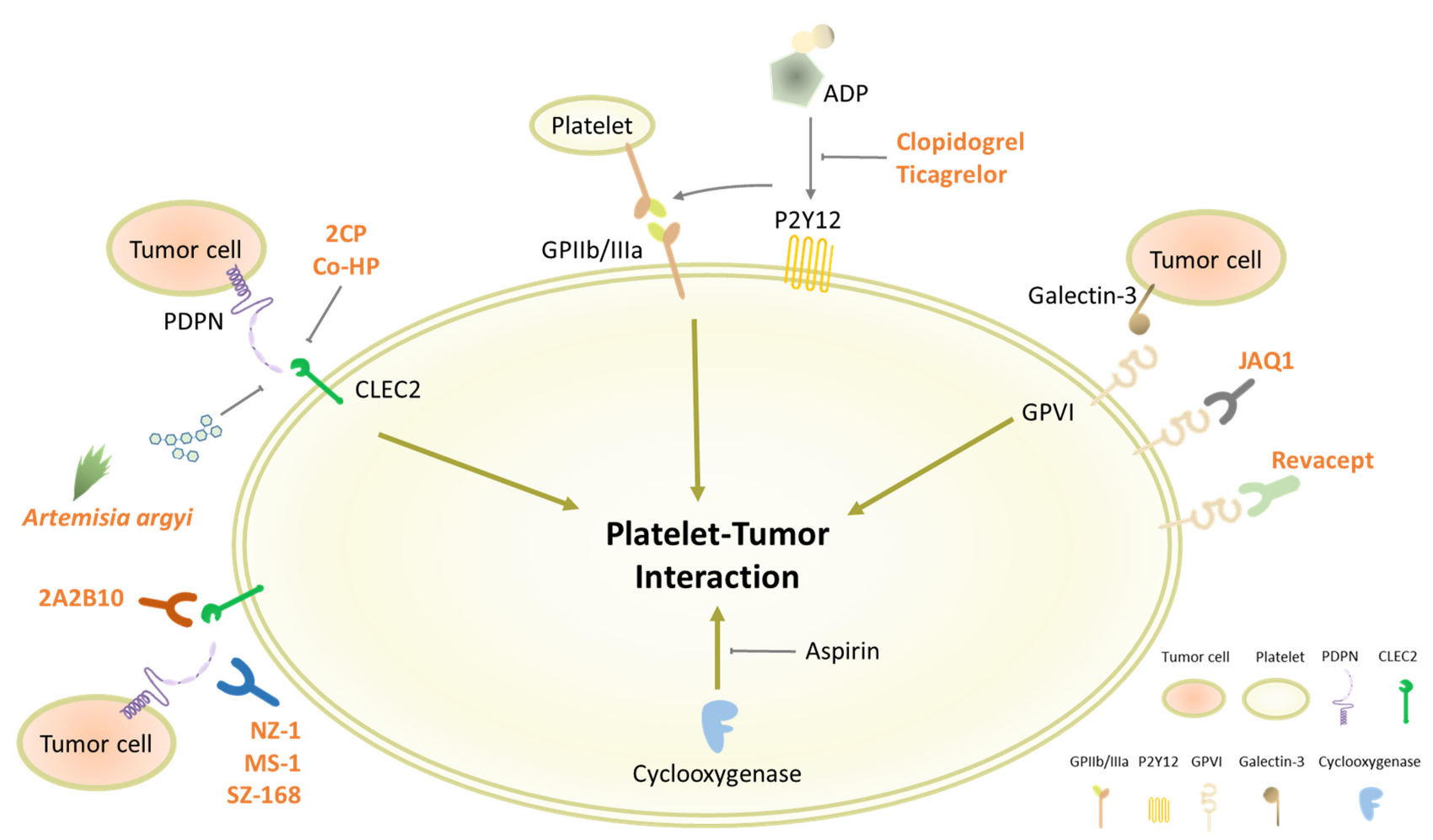

FIGURE 2 | Platelet receptors involved in platelet-tumor interaction. Platelets contain various types of receptors on the cell surface for diverse physiological functions, including cell adhesion and aggregation. Some of the surface molecules, such as CLEC2, P2Y12, and GPVI, can promote the interaction between platelets and cancer cells, which could be plausible targets for blocking TCIPA formation.

PDPN specifically inhibit platelet-tumor interaction and tumor metastasis. Although the influence of CLEC2 deficiency on bleeding is conflicting in CLEC2-null mice, CLEC2 mAbtreated mice had no sign of prolonged bleeding compared to control mice $(123,129,206,207)$. Overall, CLEC2 neutralization seems not to affect bleeding time profoundly.

In addition to neutralizing antibodies, pharmacological inhibitors display potent inhibitory effects on the CLEC2PDPN axis. Chang et al. have newly synthesized a noncytotoxic 5-nitrobenzoate compound 2CP that specifically inhibits the CLEC2-PDPN interaction (195). 2CP selectively blocked PDPN-induced TCIPA formation and lung metastasis in the xenograft model, whereas bleeding time was not affected by 2CP (195). Co-HP can directly bind to CLEC2 at PDPNbinding sites and potently block CLEC2-PDPN interaction (126). Co-HP injection significantly reduced tumor metastasis and the incidence of VTE in mice, but not affecting the bleeding time (126). Moreover, a bioactive polysaccharide extracted from Artemisia argyi leaves inhibited CLEC2-PDPN interaction and PDPN-dependent TCIPA formation (196).

Taken together, inhibition of the platelet CLEC2-PDPN axis is a promising chemotherapeutic strategy by suppressing TCIPA formation and metastasis (Table 1). In particular, targeting the CLEC2-PDPN axis seems to be a relatively safer approach to block platelet-tumor interaction without severe adverse effects, such as increased bleeding risk. Further clinical studies are needed to validate their anti-thrombotic and anti-metastatic effects in human subjects. Although targeting the CLEC2PDPN axis is relatively harmless, it still requires caution to be clinically applied, since CLEC2- or PDPN-deficient mice showed abnormal lymphatic vessel formation (123).

\section{CONCLUSION}

Despite advances in surgical techniques and therapeutic strategies including radiotherapy and immunotherapy, the survival rate of OSCC has not been improved for the past decade due to failure of local control of primary tumor $(2,208)$. Currently, platelets are well recognized as a stromal member of the TME and an important prognostic index in OSCC patients $(25,57,89)$. In particular, platelets directly interact with cancer cells via CLEC2-PDPN binding, fortifying metastatic potentials of cancer cells. Regarding that PDPN is the only known endogenous ligand for CLEC2, the platelet CLEC2-PDPN axis is a pinpoint target to control TCIPA formation-mediated metastasis without undesirable complications. Thus, blockade of the CLEC2-PDPN axis could be a prospective strategy for successful local control and improvement of survival in OSCC patients, which merits further pre-clinical and clinical investigations. 


\section{AUTHOR CONTRIBUTIONS}

N-YS contributed to study conception. S-YP, B-OH, ESC, XZ, SKL, H-JA, K-SC, W-YC, and N-YS performed literature review and analysis and revised the manuscript. N-YS, S-YP, and B-OH drafted the manuscript, figures, and tables. All authors contributed to the article and approved the submitted version.

\section{REFERENCES}

1. Chow LQM. Head and Neck Cancer. N Engl J Med (2020) 382(1):60-72. doi: 10.1056/NEJMra1715715

2. Bugshan A, Farooq I. Oral Squamous Cell Carcinoma: Metastasis, Potentially Associated Malignant Disorders, Etiology and Recent Advancements in Diagnosis. F1000Res (2020) 9:229. doi: 10.12688/ f1000research.22941.1

3. Nikoloudaki G, Creber K, Hamilton DW. Wound Healing and Fibrosis: A Contrasting Role for Periostin in Skin and the Oral Mucosa. Am J Physiol Cell Physiol (2020) 318(6):C1065-77. doi: 10.1152/ajpcell.00035.2020

4. An YZ, Cho E, Ling J, Zhang X. The Axin2-Snail Axis Promotes Bone Invasion by Activating Cancer-Associated Fibroblasts in Oral Squamous Cell Carcinoma. BMC Cancer (2020) 20(1):987. doi: 10.1186/s12885-02007495-9

5. Zainab H, Sultana AShaimaa. Stromal Desmoplasia as a Possible Prognostic Indicator in Different Grades of Oral Squamous Cell Carcinoma. J Oral Maxillofac Pathol (2019) 23(3):338-43. doi: 10.4103/ jomfp.JOMFP_136_19

6. Dourado MR, Miwa KYM, Hamada GB, Paranaiba LMR, Sawazaki-Calone I, Domingueti CB, et al. Prognostication for Oral Squamous Cell Carcinoma Patients Based on the Tumour-Stroma Ratio and Tumour Budding. Histopathology (2020) 76(6):906-18. doi: 10.1111/his.14070

7. Huang S, Cai H, Song F, Zhu Y, Hou C, Hou J. Tumor-Stroma Ratio is a Crucial Histological Predictor of Occult Cervical Lymph Node Metastasis and Survival in Early-Stage (Ct1/2N0) Oral Squamous Cell Carcinoma. Int J Oral Maxillofac Surg (2021). doi: 10.1016/j.ijom.2021.06.011

8. Vucicevic Boras V, Fucic A, Virag M, Gabric D, Blivajs I, TomasovicLoncaric C, et al. Significance of Stroma in Biology of Oral Squamous Cell Carcinoma. Tumori (2018) 104(1):9-14. doi: 10.5301/tj.5000673

9. Siriwardena S, Tsunematsu T, Qi G, Ishimaru N, Kudo Y. Invasion-Related Factors as Potential Diagnostic and Therapeutic Targets in Oral Squamous Cell Carcinoma-A Review. Int J Mol Sci (2018) 19(5):1462. doi: 10.3390/ ijms19051462

10. Caldeira PC, Soto AML, de Aguiar MCF, Martins CC. Tumor Depth of Invasion and Prognosis of Early-Stage Oral Squamous Cell Carcinoma: A Meta-Analysis. Oral Dis (2020) 26(7):1357-65. doi: 10.1111/odi.13194

11. Gremmel T, Frelinger AL3rd, Michelson AD. Platelet Physiology. Semin Thromb Hemost (2016) 42(3):191-204. doi: 10.1055/s-0035-1564835

12. Holinstat M. Normal Platelet Function. Cancer Metastasis Rev (2017) 36 (2):195-8. doi: 10.1007/s10555-017-9677-x

13. Machlus KR, Italiano JE Jr. The Incredible Journey: From Megakaryocyte Development to Platelet Formation. J Cell Biol (2013) 201(6):785-96. doi: $10.1083 /$ jcb.201304054

14. Gay LJ, Felding-Habermann B. Platelets Alter Tumor Cell Attributes to Propel Metastasis: Programming in Transit. Cancer Cell (2011) 20(5):553-4. doi: 10.1016/j.ccr.2011.11.001

15. Haemmerle M, Taylor ML, Gutschner T, Pradeep S, Cho MS, Sheng J, et al. Platelets Reduce Anoikis and Promote Metastasis by Activating YAP1 Signaling. Nat Commun (2017) 8(1):310. doi: 10.1038/s41467-017-00411-Z

16. Miao Y, Xu Z, Feng W, Zheng M, Xu Z, Gao H, et al. Platelet Infiltration Predicts Survival in Postsurgical Colorectal Cancer Patients. Int J Cancer (2021). doi: 10.1002/ijc.33816

17. Xu SS, Xu HX, Wang WQ, Li S, Li H, Li TJ, et al. Tumor-Infiltrating Platelets Predict Postoperative Recurrence and Survival in Resectable Pancreatic Neuroendocrine Tumor. World J Gastroenterol (2019) 25(41):6248-57. doi: $10.3748 /$ wjg.v25.i41.6248

\section{FUNDING}

This research was supported by National Research Foundation of Korea (NRF) Grants funded by the Korean Government (grant numbers NRF-2020R1C1C1003338 and NRF-2016R1A5A2008630 to N-YS) and by the Yonsei University Research Fund of 2021 (Yonsei Signature Research Cluster Program 2021-22-0017).

18. Zhang SR, Yao L, Wang WQ, Xu JZ, Xu HX, Jin W, et al. Tumor-Infiltrating Platelets Predict Postsurgical Survival in Patients With Pancreatic Ductal Adenocarcinoma. Ann Surg Oncol (2018) 25(13):3984-93. doi: 10.1245/ s10434-018-6727-8

19. Labelle M, Begum S, Hynes RO. Direct Signaling Between Platelets and Cancer Cells Induces an Epithelial-Mesenchymal-Like Transition and Promotes Metastasis. Cancer Cell (2011) 20(5):576-90. doi: 10.1016/ j.ccr.2011.09.009

20. Labelle M, Begum S, Hynes RO. Platelets Guide the Formation of Early Metastatic Niches. Proc Natl Acad Sci USA (2014) 111(30):E3053-61. doi: $10.1073 /$ pnas. 1411082111

21. Wang S, Li Z, Xu R. Human Cancer and Platelet Interaction, a Potential Therapeutic Target. Int J Mol Sci (2018) 19(4):1246. doi: 10.3390/ijms19041246

22. Lowe KL, Navarro-Nunez L, Watson SP. Platelet CLEC-2 and Podoplanin in Cancer Metastasis. Thromb Res (2012) 129(Suppl 1):S30-7. doi: 10.1016/ S0049-3848(12)70013-0

23. Asghar S, Parvaiz F, Manzoor S. Multifaceted Role of Cancer Educated Platelets in Survival of Cancer Cells. Thromb Res (2019) 177:42-50. doi: 10.1016/j.thromres.2019.02.026

24. Ikeda M, Furukawa $H$, Imamura $H$, Shimizu J, Ishida $H$, Masutani S, et al. Poor Prognosis Associated With Thrombocytosis in Patients With Gastric Cancer. Ann Surg Oncol (2002) 9(3):287-91. doi: 10.1007/BF02573067

25. Rachidi S, Wallace K, Day TA, Alberg AJ, Li Z. Lower Circulating Platelet Counts and Antiplatelet Therapy Independently Predict Better Outcomes in Patients With Head and Neck Squamous Cell Carcinoma. J Hematol Oncol (2014) 7:65. doi: 10.1186/s13045-014-0065-5

26. Tsoi KKF, Ho JMW, Chan FCH, Sung JJY. Long-Term Use of Low-Dose Aspirin for Cancer Prevention: A 10-Year Population Cohort Study in Hong Kong. Int J Cancer (2019) 145(1):267-73. doi: 10.1002/ijc.32083

27. Thun MJ, Jacobs EJ, Patrono C. The Role of Aspirin in Cancer Prevention. Nat Rev Clin Oncol (2012) 9(5):259-67. doi: 10.1038/nrclinonc.2011.199

28. Qiao Y, Yang T, Gan Y, Li W, Wang C, Gong Y, et al. Associations Between Aspirin Use and the Risk of Cancers: A Meta-Analysis of Observational Studies. BMC Cancer (2018) 18(1):288. doi: 10.1186/s12885-018-4156-5

29. Cea Soriano L, Vora P, Soriano-Gabarro M, Garcia Rodriguez LA. The Effect of Low-Dose Aspirin on Colorectal Cancer Prevention and Gastrointestinal Bleeding According to Bodyweight and Body Mass Index: Analysis of UK Primary Care Data. Int J Cardiol (2019) 297:135-9. doi: 10.1016/ j.ijcard.2019.08.001

30. Garcia Rodriguez LA, Martin-Perez M, Hennekens CH, Rothwell PM, Lanas A. Bleeding Risk With Long-Term Low-Dose Aspirin: A Systematic Review of Observational Studies. PloS One (2016) 11(8):e0160046. doi: 10.1371/ journal.pone.0160046

31. Flaumenhaft R. Molecular Basis of Platelet Granule Secretion. Arterioscler Thromb Vasc Biol (2003) 23(7):1152-60. doi: 10.1161/01.ATV.0000075965.88456.48

32. Maraz A, Furak J, Varga Z, Kahan Z, Tiszlavicz L, Hideghety K. Thrombocytosis Has a Negative Prognostic Value in Lung Cancer Anticancer Res (2013) 33(4):1725-9.

33. Stone RL, Nick AM, McNeish IA, Balkwill F, Han HD, Bottsford-Miller J, et al. Paraneoplastic Thrombocytosis in Ovarian Cancer. N Engl J Med (2012) 366(7):610-8. doi: 10.1056/NEJMoa1110352

34. Suzuki K, Aiura K, Kitagou M, Hoshimoto S, Takahashi S, Ueda M, et al. Platelets Counts Closely Correlate With the Disease-Free Survival Interval of Pancreatic Cancer Patients. Hepatogastroenterology (2004) 51(57):847-53.

35. Jurasz P, Sawicki G, Duszyk M, Sawicka J, Miranda C, Mayers I, et al. Matrix Metalloproteinase 2 in Tumor Cell-Induced Platelet Aggregation: Regulation by Nitric Oxide. Cancer Res (2001) 61(1):376-82. 
36. Tsuruo T, Fujita N. Platelet Aggregation in the Formation of Tumor Metastasis. Proc Jpn Acad Ser B Phys Biol Sci (2008) 84(6):189-98. doi: $10.2183 /$ pjab.84.189

37. Haemmerle M, Bottsford-Miller J, Pradeep S, Taylor ML, Choi HJ, Hansen JM, et al. FAK Regulates Platelet Extravasation and Tumor Growth After Antiangiogenic Therapy Withdrawal. J Clin Invest (2016) 126(5):1885-96. doi: $10.1172 / \mathrm{JCI} 85086$

38. Khorana AA. Venous Thromboembolism and Prognosis in Cancer. Thromb Res (2010) 125(6):490-3. doi: 10.1016/j.thromres.2009.12.023

39. Gu D, Szallasi A. Thrombocytosis Portends Adverse Prognosis in Colorectal Cancer: A Meta-Analysis of 5,619 Patients in 16 Individual Studies. Anticancer Res (2017) 37(9):4717-26. doi: 10.21873/anticanres.11878

40. Bensalah K, Leray E, Fergelot P, Rioux-Leclercq N, Tostain J, Guille F, et al. Prognostic Value of Thrombocytosis in Renal Cell Carcinoma. J Urol (2006) 175(3 Pt 1):859-63. doi: 10.1016/S0022-5347(05)00526-4

41. Gay LJ, Felding-Habermann B. Contribution of Platelets to Tumour Metastasis. Nat Rev Cancer (2011) 11(2):123-34. doi: 10.1038/nrc3004

42. Yuan L, Liu X. Platelets are Associated With Xenograft Tumor Growth and the Clinical Malignancy of Ovarian Cancer Through an AngiogenesisDependent Mechanism. Mol Med Rep (2015) 11(4):2449-58. doi: 10.3892/ mmr.2014.3082

43. Alexandrakis MG, Passam FH, Moschandrea IA, Christophoridou AV, Pappa CA, Coulocheri SA, et al. Levels of Serum Cytokines and Acute Phase Proteins in Patients With Essential and Cancer-Related Thrombocytosis. Am J Clin Oncol (2003) 26(2):135-40. doi: 10.1097/ 00000421-200304000-00007

44. Kaser A, Brandacher G, Steurer W, Kaser S, Offner FA, Zoller H, et al. Interleukin-6 Stimulates Thrombopoiesis Through Thrombopoietin: Role in Inflammatory Thrombocytosis. Blood (2001) 98(9):2720-5. doi: 10.1182/ blood.v98.9.2720

45. Senchenkova EY, Komoto S, Russell J, Almeida-Paula LD, Yan LS, Zhang S, et al. Interleukin-6 Mediates the Platelet Abnormalities and Thrombogenesis Associated With Experimental Colitis. Am J Pathol (2013) 183(1):173-81. doi: 10.1016/j.ajpath.2013.03.014

46. Rossi JF, Lu ZY, Jourdan M, Klein B. Interleukin-6 as a Therapeutic Target. Clin Cancer Res (2015) 21(6):1248-57. doi: 10.1158/1078-0432.CCR-142291

47. Ho LJ, Luo SF, Lai JH. Biological Effects of Interleukin-6: Clinical Applications in Autoimmune Diseases and Cancers. Biochem Pharmacol (2015) 97(1):16-26. doi: 10.1016/j.bcp.2015.06.009

48. Heink S, Yogev N, Garbers C, Herwerth M, Aly L, Gasperi C, et al. TransPresentation of IL-6 by Dendritic Cells Is Required for the Priming of Pathogenic TH17 Cells. Nat Immunol (2017) 18(1):74-85. doi: 10.1038/ni.3632

49. Wang M, Zhao J, Zhang L, Wei F, Lian Y, Wu Y, et al. Role of Tumor Microenvironment in Tumorigenesis. J Cancer (2017) 8(5):761-73. doi: $10.7150 /$ jca. 17648

50. Baghban R, Roshangar L, Jahanban-Esfahlan R, Seidi K, Ebrahimi-Kalan A, Jaymand M, et al. Tumor Microenvironment Complexity and Therapeutic Implications at a Glance. Cell Commun Signal (2020) 18(1):59. doi: 10.1186/ s12964-020-0530-4

51. Naba A, Clauser KR, Ding H, Whittaker CA, Carr SA, Hynes RO. The Extracellular Matrix: Tools and Insights for the "Omics" Era. Matrix Biol (2016) 49:10-24. doi: 10.1016/j.matbio.2015.06.003

52. Winkler J, Abisoye-Ogunniyan A, Metcalf KJ, Werb Z. Concepts of Extracellular Matrix Remodelling in Tumour Progression and Metastasis. Nat Commun (2020) 11(1):5120. doi: 10.1038/s41467-020-18794-x

53. Sahai E, Astsaturov I, Cukierman E, DeNardo DG, Egeblad M, Evans RM, et al. A Framework for Advancing Our Understanding of Cancer-Associated Fibroblasts. Nat Rev Cancer (2020) 20(3):174-86. doi: 10.1038/s41568-0190238-1

54. Sugimoto H, Mundel TM, Kieran MW, Kalluri R. Identification of Fibroblast Heterogeneity in the Tumor Microenvironment. Cancer Biol Ther (2006) 5 (12):1640-6. doi: 10.4161/cbt.5.12.3354

55. Qi C, Li B, Guo S, Wei B, Shao C, Li J, et al. P-Selectin-Mediated Adhesion Between Platelets and Tumor Cells Promotes Intestinal Tumorigenesis in Apc(Min/+) Mice. Int J Biol Sci (2015) 11(6):679-87. doi: 10.7150/ijbs.11589

56. Xu H, He A, Liu A, Tong W, Cao D. Evaluation of the Prognostic Role of Platelet-Lymphocyte Ratio in Cancer Patients Treated With Immune
Checkpoint Inhibitors: A Systematic Review and Meta-Analysis. Int Immunopharmacol (2019) 77:105957. doi: 10.1016/j.intimp.2019.105957

57. Yan M, Jurasz P. The Role of Platelets in the Tumor Microenvironment: From Solid Tumors to Leukemia. Biochim Biophys Acta (2016) 1863(3):392400. doi: 10.1016/j.bbamcr.2015.07.008

58. Miyashita T, Tajima H, Gabata R, Okazaki M, Shimbashi H, Ohbatake Y, et al. Impact of Extravasated Platelet Activation and Podoplanin-Positive Cancer-Associated Fibroblasts in Pancreatic Cancer Stroma. Anticancer Res (2019) 39(10):5565-72. doi: 10.21873/anticanres.13750

59. Kojima Y, Acar A, Eaton EN, Mellody KT, Scheel C, Ben-Porath I, et al. Autocrine TGF-Beta and Stromal Cell-Derived Factor-1 (SDF-1) Signaling Drives the Evolution of Tumor-Promoting Mammary Stromal Myofibroblasts. Proc Natl Acad Sci USA (2010) 107(46):20009-14. doi: 10.1073/pnas.1013805107

60. Calon A, Espinet E, Palomo-Ponce S, Tauriello DV, Iglesias M, Cespedes MV, et al. Dependency of Colorectal Cancer on a TGF-Beta-Driven Program in Stromal Cells for Metastasis Initiation. Cancer Cell (2012) 22(5):571-84. doi: 10.1016/j.ccr.2012.08.013

61. Anderberg C, Li H, Fredriksson L, Andrae J, Betsholtz C, Li X, et al. Paracrine Signaling by Platelet-Derived Growth Factor-CC Promotes Tumor Growth by Recruitment of Cancer-Associated Fibroblasts. Cancer Res (2009) 69(1):369-78. doi: 10.1158/0008-5472.CAN-08-2724

62. Karagiannis GS, Poutahidis T, Erdman SE, Kirsch R, Riddell RH, Diamandis EP. Cancer-Associated Fibroblasts Drive the Progression of Metastasis Through Both Paracrine and Mechanical Pressure on Cancer Tissue. Mol Cancer Res (2012) 10(11):1403-18. doi: 10.1158/1541-7786.MCR-12-0307

63. Yan M, Lesyk G, Radziwon-Balicka A, Jurasz P. Pharmacological Regulation of Platelet Factors That Influence Tumor Angiogenesis. Semin Oncol (2014) 41(3):370-7. doi: 10.1053/j.seminoncol.2014.04.007

64. Li R, Ren M, Chen N, Luo M, Deng X, Xia J, et al. Presence of Intratumoral Platelets is Associated With Tumor Vessel Structure and Metastasis. BMC Cancer (2014) 14:167. doi: 10.1186/1471-2407-14-167

65. Zhang N, Zhang WJ, Cai HQ, Liu HL, Peng L, Li CH, et al. Platelet Adhesion and Fusion to Endothelial Cell Facilitate the Metastasis of Tumor Cell in Hypoxia-Reoxygenation Condition. Clin Exp Metastasis (2011) 28(1):1-12. doi: 10.1007/s10585-010-9353-9

66. van Zijl F, Krupitza G, Mikulits W. Initial Steps of Metastasis: Cell Invasion and Endothelial Transmigration. Mutat Res (2011) 728(1-2):23-34. doi: 10.1016/j.mrrev.2011.05.002

67. Bai YY, Du L, Jing L, Tian T, Liang X, Jiao M, et al. Clinicopathological and Prognostic Significance of Pretreatment Thrombocytosis in Patients With Endometrial Cancer: A Meta-Analysis. Cancer Manag Res (2019) 11:428395. doi: 10.2147/CMAR.S186535

68. Ichikawa J, Ando T, Kawasaki T, Sasaki T, Shirai T, Tsukiji N, et al. Role of Platelet C-Type Lectin-Like Receptor 2 in Promoting Lung Metastasis in Osteosarcoma. J Bone Miner Res (2020) 35(9):1738-50. doi: 10.1002/jbmr.4045

69. Papa AL, Jiang A, Korin N, Chen MB, Langan ET, Waterhouse A, et al. Platelet Decoys Inhibit Thrombosis and Prevent Metastatic Tumor Formation in Preclinical Models. Sci Transl Med (2019) 11(479):eaau5898. doi: $10.1126 /$ scitranslmed.aau5898

70. Miyashita T, Tajima H, Makino I, Nakagawara H, Kitagawa H, Fushida S, et al. Metastasis-Promoting Role of Extravasated Platelet Activation in Tumor. J Surg Res (2015) 193(1):289-94. doi: 10.1016/j.jss.2014.07.037

71. Karolczak K, Watala C. Blood Platelets as an Important But Underrated Circulating Source of TGFbeta. Int J Mol Sci (2021) 22(9):4492. doi: 10.3390/ ijms22094492

72. Guo Y, Cui W, Pei Y, Xu D. Platelets Promote Invasion and Induce Epithelial to Mesenchymal Transition in Ovarian Cancer Cells by TGFBeta Signaling Pathway. Gynecol Oncol (2019) 153(3):639-50. doi: 10.1016/ j.ygyno.2019.02.026

73. Wang Y, Sun Y, Li D, Zhang L, Wang K, Zuo Y, et al. Platelet P2Y12 is Involved in Murine Pulmonary Metastasis. PloS One (2013) 8(11):e80780. doi: 10.1371/journal.pone. 0080780

74. Hu Q, Hisamatsu T, Haemmerle M, Cho MS, Pradeep S, Rupaimoole R, et al. Role of Platelet-Derived Tgfbetal in the Progression of Ovarian Cancer. Clin Cancer Res (2017) 23(18):5611-21. doi: 10.1158/1078-0432.CCR-16-3272

75. Kazes I, Elalamy I, Sraer JD, Hatmi M, Nguyen G. Platelet Release of Trimolecular Complex Components MT1-MMP/TIMP2/MMP2: 
Involvement in MMP2 Activation and Platelet Aggregation. Blood (2000) 96 (9):3064-9. doi: 10.1182/blood.V96.9.3064

76. Falcinelli E, Giannini S, Boschetti E, Gresele P. Platelets Release Active Matrix Metalloproteinase-2 In Vivo in Humans at a Site of Vascular Injury: Lack of Inhibition by Aspirin. Br J Haematol (2007) 138(2):221-30. doi: 10.1111/j.1365-2141.2007.06632.x

77. Janowska-Wieczorek A, Wysoczynski M, Kijowski J, Marquez-Curtis L, Machalinski B, Ratajczak J, et al. Microvesicles Derived From Activated Platelets Induce Metastasis and Angiogenesis in Lung Cancer. Int J Cancer (2005) 113(5):752-60. doi: 10.1002/ijc.20657

78. Dashevsky O, Varon D, Brill A. Platelet-Derived Microparticles Promote Invasiveness of Prostate Cancer Cells via Upregulation of MMP-2 Production. Int J Cancer (2009) 124(8):1773-7. doi: 10.1002/ijc.24016

79. Shin MK, Lee JW, Kim YI, Kim YO, Seok H, Kim NI. The Effects of PlateletRich Clot Releasate on the Expression of MMP-1 and Type I Collagen in Human Adult Dermal Fibroblasts: PRP Is a Stronger MMP-1 Stimulator. Mol Biol Rep (2014) 41(1):3-8. doi: 10.1007/s11033-013-2718-9

80. Zuo XX, Yang Y, Zhang Y, Zhang ZG, Wang XF, Shi YG. Platelets Promote Breast Cancer Cell MCF-7 Metastasis by Direct Interaction: Surface Integrin Alpha2beta1-Contacting-Mediated Activation of Wnt-Beta-Catenin Pathway. Cell Commun Signal (2019) 17(1):142. doi: 10.1186/s12964-0190464-x

81. Semple JW, Italiano JE Jr, Freedman J. Platelets and the Immune Continuum. Nat Rev Immunol (2011) 11(4):264-74. doi: 10.1038/nri2956

82. Dunn GP, Bruce AT, Ikeda H, Old LJ, Schreiber RD. Cancer Immunoediting: From Immunosurveillance to Tumor Escape. Nat Immunol (2002) 3(11):991-8. doi: 10.1038/ni1102-991

83. Kopp HG, Placke T, Salih HR. Platelet-Derived Transforming Growth Factor-Beta Down-Regulates NKG2D Thereby Inhibiting Natural Killer Cell Antitumor Reactivity. Cancer Res (2009) 69(19):7775-83. doi: 10.1158/0008-5472.CAN-09-2123

84. Placke T, Orgel M, Schaller M, Jung G, Rammensee HG, Kopp HG, et al. Platelet-Derived MHC Class I Confers a Pseudonormal Phenotype to Cancer Cells That Subverts the Antitumor Reactivity of Natural Killer Immune Cells. Cancer Res (2012) 72(2):440-8. doi: 10.1158/0008-5472.CAN-11-1872

85. Placke T, Salih HR, Kopp HG. GITR Ligand Provided by Thrombopoietic Cells Inhibits NK Cell Antitumor Activity. J Immunol (2012) 189(1):154-60. doi: 10.4049/jimmunol.1103194

86. Rachidi S, Metelli A, Riesenberg B, Wu BX, Nelson MH, Wallace C, et al. Platelets Subvert T Cell Immunity Against Cancer via GARP-TGFbeta Axis. Sci Immunol (2017) 2(11):eaai7911. doi: 10.1126/sciimmunol.aai7911

87. Zaslavsky AB, Adams MP, Cao X, Maj T, Choi JE, Stangl-Kremser J, et al. Platelet PD-L1 Suppresses Anti-Cancer Immune Cell Activity in PD-L1 Negative Tumors. Sci Rep (2020) 10(1):19296. doi: 10.1038/s41598-02076351-4

88. Riesenberg BP, Ansa-Addo EA, Gutierrez J, Timmers CD, Liu B, Li Z. Cutting Edge: Targeting Thrombocytes to Rewire Anticancer Immunity in the Tumor Microenvironment and Potentiate Efficacy of PD-1 Blockade. J Immunol (2019) 203(5):1105-10. doi: 10.4049/jimmunol.1900594

89. Furlan C, Steffan A, Polesel J, Trovo M, Gobitti C, Vaccher E, et al. Lower Platelet Counts and Antiplatelet Therapy Independently Predict Better Outcomes in Patients With Head and Neck Squamous Cell Carcinoma: A Retrospective Analysis. biomark Res (2015) 3:25. doi: 10.1186/s40364-0150051-2

90. Lu CC, Chang KW, Chou FC, Cheng CY, Liu CJ. Association of Pretreatment Thrombocytosis With Disease Progression and Survival in Oral Squamous Cell Carcinoma. Oral Oncol (2007) 43(3):283-8. doi: 10.1016/j.oraloncology.2006.03.010

91. Brown JS, Lowe D, Kalavrezos N, D'Souza J, Magennis P, Woolgar J. Patterns of Invasion and Routes of Tumor Entry Into the Mandible by Oral Squamous Cell Carcinoma. Head Neck (2002) 24(4):370-83. doi: 10.1002/hed.10062

92. Jimi E, Furuta H, Matsuo K, Tominaga K, Takahashi T, Nakanishi O. The Cellular and Molecular Mechanisms of Bone Invasion by Oral Squamous Cell Carcinoma. Oral Dis (2011) 17(5):462-8. doi: 10.1111/j.16010825.2010.01781.x

93. Shaw RJ, Brown JS, Woolgar JA, Lowe D, Rogers SN, Vaughan ED. The Influence of the Pattern of Mandibular Invasion on Recurrence and Survival in Oral Squamous Cell Carcinoma. Head Neck (2004) 26(10):861-9. doi: 10.1002/hed.20036

94. Bakewell SJ, Nestor P, Prasad S, Tomasson MH, Dowland N, Mehrotra M, et al. Platelet and Osteoclast Beta3 Integrins Are Critical for Bone Metastasis. Proc Natl Acad Sci USA (2003) 100(24):14205-10. doi: 10.1073/ pnas. 2234372100

95. Uluckan O, Eagleton MC, Floyd DH, Morgan EA, Hirbe AC, Kramer M, et al. APT102, A Novel Adpase, Cooperates With Aspirin to Disrupt Bone Metastasis in Mice. J Cell Biochem (2008) 104(4):1311-23. doi: 10.1002/jcb.21709

96. Boucharaba A, Serre CM, Gres S, Saulnier-Blache JS, Bordet JC, Guglielmi J, et al. Platelet-Derived Lysophosphatidic Acid Supports the Progression of Osteolytic Bone Metastases in Breast Cancer. J Clin Invest (2004) 114 (12):1714-25. doi: 10.1172/JCI22123

97. Ward Y, Lake R, Faraji F, Sperger J, Martin P, Gilliard C, et al. Platelets Promote Metastasis via Binding Tumor CD97 Leading to Bidirectional Signaling That Coordinates Transendothelial Migration. Cell Rep (2018) 23(3):808-22. doi: 10.1016/j.celrep.2018.03.092

98. Goda T, Shimo T, Yoshihama Y, Hassan NM, Ibaragi S, Kurio N, et al. Bone Destruction by Invading Oral Squamous Carcinoma Cells Mediated by the Transforming Growth Factor-Beta Signalling Pathway. Anticancer Res (2010) 30(7):2615-23.

99. Son SH, Park J, Jung MJ, Lee SK, Kim H, Kim KR, et al. Transforming Growth Factor-Beta-Regulated Fractalkine as a Marker of Erosive Bone Invasion in Oral Squamous Cell Carcinoma. Eur J Oral Sci (2021) 129(1): e12750. doi: 10.1111/eos. 12750

100. Astarita JL, Acton SE, Turley SJ. Podoplanin: Emerging Functions in Development, the Immune System, and Cancer. Front Immunol (2012) 3:283. doi: 10.3389/fimmu.2012.00283

101. Ramirez MI, Millien G, Hinds A, Cao Y, Seldin DC, Williams MC. T1alpha, a Lung Type I Cell Differentiation Gene, is Required for Normal Lung Cell Proliferation and Alveolus Formation at Birth. Dev Biol (2003) 256(1):61-72. doi: 10.1016/s0012-1606(02)00098-2

102. Schacht V, Ramirez MI, Hong YK, Hirakawa S, Feng D, Harvey N, et al. T1alpha/podoplanin Deficiency Disrupts Normal Lymphatic Vasculature Formation and Causes Lymphedema. EMBO J (2003) 22(14):3546-56. doi: 10.1093/emboj/cdg342

103. Peters A, Pitcher LA, Sullivan JM, Mitsdoerffer M, Acton SE, Franz B, et al. Th17 Cells Induce Ectopic Lymphoid Follicles in Central Nervous System Tissue Inflammation. Immunity (2011) 35(6):986-96. doi: 10.1016/ j.immuni.2011.10.015

104. Shibahara J, Kashima T, Kikuchi Y, Kunita A, Fukayama M. Podoplanin is Expressed in Subsets of Tumors of the Central Nervous System. Virchows Arch (2006) 448(4):493-9. doi: 10.1007/s00428-005-0133-x

105. Kato Y, Kaneko M, Sata M, Fujita N, Tsuruo T, Osawa M. Enhanced Expression of Aggrus (T1alpha/podoplanin), a Platelet-AggregationInducing Factor in Lung Squamous Cell Carcinoma. Tumour Biol (2005) 26(4):195-200. doi: 10.1159/000086952

106. Wicki A, Lehembre F, Wick N, Hantusch B, Kerjaschki D, Christofori G. Tumor Invasion in the Absence of Epithelial-Mesenchymal Transition: Podoplanin-Mediated Remodeling of the Actin Cytoskeleton. Cancer Cell (2006) 9(4):261-72. doi: 10.1016/j.ccr.2006.03.010

107. Kimura N, Kimura I. Podoplanin as a Marker for Mesothelioma. Pathol Int (2005) 55(2):83-6. doi: 10.1111/j.1440-1827.2005.01791.x

108. Miyata K, Takemoto A, Okumura S, Nishio M, Fujita N. Podoplanin Enhances Lung Cancer Cell Growth In Vivo by Inducing Platelet Aggregation. Sci Rep (2017) 7(1):4059. doi: 10.1038/s41598-017-04324-1

109. Sesartic M, Ikenberg K, Yoon SY, Detmar M. Keratinocyte-Expressed Podoplanin is Dispensable for Multi-Step Skin Carcinogenesis. Cells (2020) 9(6):1542. doi: 10.3390/cells9061542

110. Grau SJ, Trillsch F, Tonn JC, Goldbrunner RH, Noessner E, Nelson PJ, et al. Podoplanin Increases Migration and Angiogenesis in Malignant Glioma. Int J Clin Exp Pathol (2015) 8(7):8663-70.

111. Scholl FG, Gamallo C, Quintanilla M. Ectopic Expression of PA2.26 Antigen in Epidermal Keratinocytes Leads to Destabilization of Adherens Junctions and Malignant Progression. Lab Invest (2000) 80(11):1749-59. doi: 10.1038/ labinvest. 3780185

112. Sikorska J, Gawel D, Domek H, Rudzinska M, Czarnocka B. Podoplanin (PDPN) Affects the Invasiveness of Thyroid Carcinoma Cells by Inducing 
Ezrin, Radixin and Moesin (E/R/M) Phosphorylation in Association With Matrix Metalloproteinases. BMC Cancer (2019) 19(1):85. doi: 10.1186/ s12885-018-5239-z

113. Wicki A, Christofori G. The Potential Role of Podoplanin in Tumour Invasion. Br J Cancer (2007) 96(1):1-5. doi: 10.1038/sj.bjc.6603518

114. Mir Seyed Nazari P, Riedl J, Pabinger I, Ay C. The Role of Podoplanin in Cancer-Associated Thrombosis. Thromb Res (2018) 164(Suppl 1):S34-9. doi: 10.1016/j.thromres.2018.01.020

115. Riedl J, Preusser M, Nazari PM, Posch F, Panzer S, Marosi C, et al. Podoplanin Expression in Primary Brain Tumors Induces Platelet Aggregation and Increases Risk of Venous Thromboembolism. Blood (2017) 129(13):1831-9. doi: 10.1182/blood-2016-06-720714

116. Sugimoto Y, Watanabe M, Oh-hara T, Sato S, Isoe T, Tsuruo T. Suppression of Experimental Lung Colonization of a Metastatic Variant of Murine Colon Adenocarcinoma 26 by a Monoclonal Antibody 8F11 Inhibiting Tumor CellInduced Platelet Aggregation. Cancer Res (1991) 51(3):921-5.

117. Costa B, Eisemann T, Strelau J, Spaan I, Korshunov A, Liu HK, et al. Intratumoral Platelet Aggregate Formation in a Murine Preclinical Glioma Model Depends on Podoplanin Expression on Tumor Cells. Blood Adv (2019) 3(7):1092-102. doi: 10.1182/bloodadvances.2018015966

118. Campello E, Ilich A, Simioni P, Key NS. The Relationship Between Pancreatic Cancer and Hypercoagulability: A Comprehensive Review on Epidemiological and Biological Issues. Br J Cancer (2019) 121(5):359-71. doi: 10.1038/s41416-019-0510-x

119. Xu M, Wang X, Pan Y, Zhao X, Yan B, Ruan C, et al. Blocking Podoplanin Suppresses Growth and Pulmonary Metastasis of Human Malignant Melanoma. BMC Cancer (2019) 19(1):599. doi: 10.1186/s12885-019-5808-9

120. Takemoto A, Okitaka M, Takagi S, Takami M, Sato S, Nishio M, et al. A Critical Role of Platelet TGF-Beta Release in Podoplanin-Mediated Tumour Invasion and Metastasis. Sci Rep (2017) 7:42186. doi: 10.1038/srep42186

121. Takemoto A, Miyata K, Fujita N. Platelet-Activating Factor Podoplanin: From Discovery to Drug Development. Cancer Metastasis Rev (2017) 36 (2):225-34. doi: 10.1007/s10555-017-9672-2

122. Suzuki-Inoue K. Roles of the CLEC-2-Podoplanin Interaction in Tumor Progression. Platelets (2018) 4:1-7. doi: 10.1080/09537104.2018.1478401

123. Suzuki-Inoue K, Inoue O, Ding G, Nishimura S, Hokamura K, Eto K, et al. Essential In Vivo Roles of the C-Type Lectin Receptor CLEC-2: Embryonic/ Neonatal Lethality of CLEC-2-Deficient Mice by Blood/Lymphatic Misconnections and Impaired Thrombus Formation of CLEC-2-Deficient Platelets. J Biol Chem (2010) 285(32):24494-507. doi: 10.1074/jbc.M110.130575

124. Payne H, Ponomaryov T, Watson SP, Brill A. Mice With a Deficiency in CLEC-2 Are Protected Against Deep Vein Thrombosis. Blood (2017) 129 (14):2013-20. doi: 10.1182/blood-2016-09-742999

125. Suzuki-Inoue K, Kato Y, Inoue O, Kaneko MK, Mishima K, Yatomi Y, et al. Involvement of the Snake Toxin Receptor CLEC-2, in Podoplanin-Mediated Platelet Activation, by Cancer Cells. J Biol Chem (2007) 282(36):25993-6001. doi: 10.1074/jbc.M702327200

126. Tsukiji N, Osada M, Sasaki T, Shirai T, Satoh K, Inoue O, et al. Cobalt Hematoporphyrin Inhibits CLEC-2-Podoplanin Interaction, Tumor Metastasis, and Arterial/Venous Thrombosis in Mice. Blood Adv (2018) 2 (17):2214-25. doi: 10.1182/bloodadvances.2018016261

127. Shirai T, Inoue O, Tamura S, Tsukiji N, Sasaki T, Endo H, et al. C-Type Lectin-Like Receptor 2 Promotes Hematogenous Tumor Metastasis and Prothrombotic State in Tumor-Bearing Mice. J Thromb Haemost (2017) 15 (3):513-25. doi: 10.1111/jth.13604

128. Takagi S, Sato S, Oh-hara T, Takami M, Koike S, Mishima Y, et al. Platelets Promote Tumor Growth and Metastasis via Direct Interaction Between Aggrus/podoplanin and CLEC-2. PloS One (2013) 8(8):e73609. doi: 10.1371/ journal.pone.0073609

129. Bender M, May F, Lorenz V, Thielmann I, Hagedorn I, Finney BA, et al. Combined In Vivo Depletion of Glycoprotein VI and C-Type Lectin-Like Receptor 2 Severely Compromises Hemostasis and Abrogates Arterial Thrombosis in Mice. Arterioscler Thromb Vasc Biol (2013) 33(5):926-34. doi: 10.1161/ATVBAHA.112.300672

130. Martin-Villar E, Megias D, Castel S, Yurrita MM, Vilaro S, Quintanilla M. Podoplanin Binds ERM Proteins to Activate RhoA and Promote EpithelialMesenchymal Transition. J Cell Sci (2006) 119(Pt 21):4541-53. doi: 10.1242/ jcs. 03218
131. Louvet-Vallee S. ERM Proteins: From Cellular Architecture to Cell Signaling. Biol Cell (2000) 92(5):305-16. doi: 10.1016/s0248-4900(00)01078-9

132. Fievet B, Louvard D, Arpin M. ERM Proteins in Epithelial Cell Organization and Functions. Biochim Biophys Acta (2007) 1773(5):653-60. doi: 10.1016/ j.bbamcr.2006.06.013

133. Fehon RG, McClatchey AI, Bretscher A. Organizing the Cell Cortex: The Role of ERM Proteins. Nat Rev Mol Cell Biol (2010) 11(4):276-87. doi: $10.1038 / \mathrm{nrm} 2866$

134. Kawaguchi K, Yoshida S, Hatano R, Asano S. Pathophysiological Roles of Ezrin/Radixin/Moesin Proteins. Biol Pharm Bull (2017) 40(4):381-90. doi: 10.1248/bpb.b16-01011

135. Saotome I, Curto M, McClatchey AI. Ezrin is Essential for Epithelial Organization and Villus Morphogenesis in the Developing Intestine. Dev Cell (2004) 6(6):855-64. doi: 10.1016/j.devcel.2004.05.007

136. Clucas J, Valderrama F. ERM Proteins in Cancer Progression. J Cell Sci (2014) 127(Pt 2):267-75. doi: 10.1242/jcs.133108

137. Horwitz V, Davidson B, Stern D, Trope CG, Tavor Re'em T, Reich R. Ezrin Is Associated With Disease Progression in Ovarian Carcinoma. PloS One (2016) 11(9):e0162502. doi: 10.1371/journal.pone.0162502

138. Li N, Kong J, Lin Z, Yang Y, Jin T, Xu M, et al. Ezrin Promotes Breast Cancer Progression by Modulating AKT Signals. Br J Cancer (2019) 120(7):703-13. doi: 10.1038/s41416-019-0383-z

139. Pan D, Wang S, Ye H, Xu S, Ye G. Ezrin Expression in the Primary Hepatocellular Carcinoma Patients and Associated With Clinical, Pathological Characteristics. J Cancer Res Ther (2016) 12(Supplement): C291-4. doi: 10.4103/0973-1482.200761

140. Piao J, Liu S, Xu Y, Wang C, Lin Z, Qin Y, et al. Ezrin Protein Overexpression Predicts the Poor Prognosis of Pancreatic Ductal Adenocarcinomas. Exp Mol Pathol (2015) 98(1):1-6. doi: 10.1016/j.yexmp.2014.11.003

141. Wang Y, Yang Y, Wang X, Jin T, Zhu G, Lin Z. Ezrin as a Prognostic Indicator Regulates Colon Adenocarinoma Progression Through Glycolysis. J Gastroenterol Hepatol (2020) 36(3):710-20. doi: 10.1111/jgh.15195

142. Cui Y, Wu J, Zong M, Song G, Jia Q, Jiang J, et al. Proteomic Profiling in Pancreatic Cancer With and Without Lymph Node Metastasis. Int J Cancer (2009) 124(7):1614-21. doi: 10.1002/ijc.24163

143. Ichikawa T, Masumoto J, Kaneko M, Saida T, Sagara J, Taniguchi S. Expression of Moesin and Its Associated Molecule CD44 in Epithelial Skin Tumors. J Cutan Pathol (1998) 25(5):237-43. doi: 10.1111/j.16000560.1998.tb01727.x

144. Kim CY, Jung WY, Lee HJ, Kim HK, Kim A, Shin BK. Proteomic Analysis Reveals Overexpression of Moesin and Cytokeratin 17 Proteins in Colorectal Carcinoma. Oncol Rep (2012) 27(3):608-20. doi: 10.3892/or.2011.1545

145. Mhawech-Fauceglia P, Wang D, Lele S, Frederick PJ, Pejovic T, Liu S. Claudin7 and Moesin in Endometrial Adenocarcinoma; A Retrospective Study of 265 Patients. BMC Res Notes (2012) 5:65. doi: 10.1186/17560500-5-65

146. Zhu X, Morales FC, Agarwal NK, Dogruluk T, Gagea M, Georgescu MM. Moesin is a Glioma Progression Marker That Induces Proliferation and Wnt/ beta-Catenin Pathway Activation via Interaction With CD44. Cancer Res (2013) 73(3):1142-55. doi: 10.1158/0008-5472.CAN-12-1040

147. Makitie T, Carpen O, Vaheri A, Kivela T. Ezrin as a Prognostic Indicator and Its Relationship to Tumor Characteristics in Uveal Malignant Melanoma. Invest Ophthalmol Vis Sci (2001) 42(11):2442-9.

148. Arumugam P, Partelli S, Coleman SJ, Cataldo I, Beghelli S, Bassi C, et al. Ezrin Expression Is an Independent Prognostic Factor in Gastro-Intestinal Cancers. J Gastrointest Surg (2013) 17(12):2082-91. doi: 10.1007/s11605013-2384-1

149. Barros FBA, Assao A, Garcia NG, Nonogaki S, Carvalho AL, Soares FA, et al. Moesin Expression by Tumor Cells Is an Unfavorable Prognostic Biomarker for Oral Cancer. BMC Cancer (2018) 18(1):53. doi: 10.1186/s12885-017-3914-0

150. Kong J, Li Y, Liu S, Jin H, Shang Y, Quan C, et al. High Expression of Ezrin Predicts Poor Prognosis in Uterine Cervical Cancer. BMC Cancer (2013) 13:520. doi: 10.1186/1471-2407-13-520

151. Fernandez-Munoz B, Yurrita MM, Martin-Villar E, Carrasco-Ramirez P, Megias D, Renart J, et al. The Transmembrane Domain of Podoplanin is Required for Its Association With Lipid Rafts and the Induction of Epithelial-Mesenchymal Transition. Int J Biochem Cell Biol (2011) 43 (6):886-96. doi: 10.1016/j.biocel.2011.02.010 
152. Zhu YW, Yan JK, Li JJ, Ou YM, Yang Q. Knockdown of Radixin Suppresses Gastric Cancer Metastasis In Vitro by Up-Regulation of E-Cadherin via NFKappab/Snail Pathway. Cell Physiol Biochem (2016) 39(6):2509-21. doi: $10.1159 / 000452518$

153. Acton SE, Astarita JL, Malhotra D, Lukacs-Kornek V, Franz B, Hess PR, et al. Podoplanin-Rich Stromal Networks Induce Dendritic Cell Motility via Activation of the C-Type Lectin Receptor CLEC-2. Immunity (2012) 37 (2):276-89. doi: 10.1016/j.immuni.2012.05.022

154. Astarita JL, Cremasco V, Fu J, Darnell MC, Peck JR, Nieves-Bonilla JM, et al. The CLEC-2-Podoplanin Axis Controls the Contractility of Fibroblastic Reticular Cells and Lymph Node Microarchitecture. Nat Immunol (2015) 16(1):75-84. doi: 10.1038/ni.3035

155. Bourne JH, Beristain-Covarrubias N, Zuidscherwoude M, Campos J, Di Y, Garlick E, et al. CLEC-2 Prevents Accumulation and Retention of Inflammatory Macrophages During Murine Peritonitis. Front Immunol (2021) 12:693974. doi: 10.3389/fimmu.2021.693974

156. Yuan P, Temam S, El-Naggar A, Zhou X, Liu DD, Lee JJ, et al. Overexpression of Podoplanin in Oral Cancer and Its Association With Poor Clinical Outcome. Cancer (2006) 107(3):563-9. doi: 10.1002/ cncr.22061

157. Retzbach EP, Sheehan SA, Nevel EM, Batra A, Phi T, Nguyen ATP, et al. Podoplanin Emerges as a Functionally Relevant Oral Cancer Biomarker and Therapeutic Target. Oral Oncol (2018) 78:126-36. doi: 10.1016/ j.oraloncology.2018.01.011

158. Kreppel M, Drebber U, Wedemeyer I, Eich HT, Backhaus T, Zoller JE, et al. Podoplanin Expression Predicts Prognosis in Patients With Oral Squamous Cell Carcinoma Treated With Neoadjuvant Radiochemotherapy. Oral Oncol (2011) 47(9):873-8. doi: 10.1016/j.oraloncology.2011.06.508

159. Kawaguchi H, El-Naggar AK, Papadimitrakopoulou V, Ren H, Fan YH, Feng L, et al. Podoplanin: A Novel Marker for Oral Cancer Risk in Patients With Oral Premalignancy. J Clin Oncol (2008) 26(3):354-60. doi: 10.1200/ JCO.2007.13.4072

160. Lee HY, Yu NY, Lee SH, Tsai HJ, Wu CC, Cheng JC, et al. Podoplanin Promotes Cancer-Associated Thrombosis and Contributes to the Unfavorable Overall Survival in an Ectopic Xenograft Mouse Model of Oral Cancer. BioMed J (2020) 43(2):146-62. doi: 10.1016/j.bj.2019.07.001

161. Huber GF, Fritzsche FR, Zullig L, Storz M, Graf N, Haerle SK, et al. Podoplanin Expression Correlates With Sentinel Lymph Node Metastasis in Early Squamous Cell Carcinomas of the Oral Cavity and Oropharynx. Int $J$ Cancer (2011) 129(6):1404-9. doi: 10.1002/ijc.25795

162. Tsuneki M, Yamazaki M, Maruyama S, Cheng J, Saku T. Podoplanin-Mediated Cell Adhesion Through Extracellular Matrix in Oral Squamous Cell Carcinoma. Lab Invest (2013) 93(8):921-32. doi: 10.1038/labinvest.2013.86

163. Mei Y, Zhang P, Zuo H, Clark D, Xia R, Li J, et al. Ebp1 Activates Podoplanin Expression and Contributes to Oral Tumorigenesis. Oncogene (2014) 33 (29):3839-50. doi: 10.1038/onc.2013.354

164. Li YY, Zhou CX, Gao Y. Podoplanin Promotes the Invasion of Oral Squamous Cell Carcinoma in Coordination With MT1-MMP and Rho GTPases. Am J Cancer Res (2015) 5(2):514-29.

165. Safi AF, Nickenig HJ, Rothamel D, Zirk M, Thiele O, Grandoch A, et al. Expression of Ezrin in Oral Squamous Cell Carcinoma: Prognostic Impact and Clinicopathological Correlations. J Craniomaxillofac Surg (2015) 43 (9):1899-905. doi: 10.1016/j.jcms.2015.08.011

166. Kobayashi H, Sagara J, Kurita H, Morifuji M, Ohishi M, Kurashina K, et al. Clinical Significance of Cellular Distribution of Moesin in Patients With Oral Squamous Cell Carcinoma. Clin Cancer Res (2004) 10(2):572-80. doi: 10.1158/1078-0432.ccr-1323-03

167. Costa YF, Tjioe KC, Nonogaki S, Soares FA, Lauris JR, Oliveira DT. Are Podoplanin and Ezrin Involved in the Invasion Process of the Ameloblastomas? Eur J Histochem (2015) 59(1):2451. doi: 10.4081/ ejh.2015.2451

168. Assao A, Nonogaki S, Lauris JRP, Carvalho AL, Pinto CAL, Soares FA, et al. Podoplanin, Ezrin, and Rho-A Proteins may Have Joint Participation in Tumor Invasion of Lip Cancer. Clin Oral Investig (2017) 21(5):1647-57. doi: 10.1007/s00784-016-1956-3

169. Bosetti C, Rosato V, Gallus S, Cuzick J, La Vecchia C. Aspirin and Cancer Risk: A Quantitative Review to 2011. Ann Oncol (2012) 23(6):1403-15. doi: 10.1093/annonc/mds113
170. Jayaprakash V, Rigual NR, Moysich KB, Loree TR, Nasca MA, Menezes RJ, et al. Chemoprevention of Head and Neck Cancer With Aspirin: A CaseControl Study. Arch Otolaryngol Head Neck Surg (2006) 132(11):1231-6. doi: 10.1001/archotol.132.11.1231

171. de la Cour CD, Verdoodt F, Aalborg GL, von Buchwald C, Friis S, Dehlendorff C, et al. Low-Dose Aspirin Use and Risk of Head and Neck Cancer-A Danish Nationwide Case-Control Study. Br J Clin Pharmacol (2021) 87(3):1561-7. doi: 10.1111/bcp.14502

172. Wilson JC, Anderson LA, Murray LJ, Hughes CM. Non-Steroidal AntiInflammatory Drug and Aspirin Use and the Risk of Head and Neck Cancer: A Systematic Review. Cancer Causes Control (2011) 22(5):803-10. doi: 10.1007/s10552-011-9751-6

173. Cooke NM, Spillane CD, Sheils O, O’Leary J, Kenny D. Aspirin and P2Y12 Inhibition Attenuate Platelet-Induced Ovarian Cancer Cell Invasion. BMC Cancer (2015) 15:627. doi: 10.1186/s12885-015-1634-x

174. Guillem-Llobat P, Dovizio M, Bruno A, Ricciotti E, Cufino V, Sacco A, et al. Aspirin Prevents Colorectal Cancer Metastasis in Mice by Splitting the Crosstalk Between Platelets and Tumor Cells. Oncotarget (2016) 7 (22):32462-77. doi: 10.18632/oncotarget.8655

175. Algra AM, Rothwell PM. Effects of Regular Aspirin on Long-Term Cancer Incidence and Metastasis: A Systematic Comparison of Evidence From Observational Studies Versus Randomised Trials. Lancet Oncol (2012) 13 (5):518-27. doi: 10.1016/S1470-2045(12)70112-2

176. Cho MS, Noh K, Haemmerle M, Li D, Park H, Hu Q, et al. Role of ADP Receptors on Platelets in the Growth of Ovarian Cancer. Blood (2017) 130 (10):1235-42. doi: 10.1182/blood-2017-02-769893

177. Pavlovic N, Kopsida M, Gerwins P, Heindryckx F. Activated Platelets Contribute to the Progression of Hepatocellular Carcinoma by Altering the Tumor Environment. Life Sci (2021) 277:119612. doi: 10.1016/ j.lfs.2021.119612

178. Gareau AJ, Brien C, Gebremeskel S, Liwski RS, Johnston B, Bezuhly M. Ticagrelor Inhibits Platelet-Tumor Cell Interactions and Metastasis in Human and Murine Breast Cancer. Clin Exp Metastasis (2018) 35(1-2):2535. doi: 10.1007/s10585-018-9874-1

179. Geranpayehvaghei M, Shi Q, Zhao B, Li S, Xu J, Taleb M, et al. Targeting Delivery of Platelets Inhibitor to Prevent Tumor Metastasis. Bioconjug Chem (2019) 30(9):2349-57. doi: 10.1021/acs.bioconjchem.9b00457

180. Gebremeskel S, LeVatte T, Liwski RS, Johnston B, Bezuhly M. The Reversible P2Y12 Inhibitor Ticagrelor Inhibits Metastasis and Improves Survival in Mouse Models of Cancer. Int J Cancer (2015) 136(1):234-40. doi: 10.1002/ ijc. 28947

181. Hicks BM, Murray LJ, Hughes C, Cardwell CR. Clopidogrel Use and CancerSpecific Mortality: A Population-Based Cohort Study of Colorectal, Breast and Prostate Cancer Patients. Pharmacoepidemiol Drug Saf (2015) 24 (8):830-40. doi: 10.1002/pds.3807

182. Elmariah S, Doros G, Benavente OR, Bhatt DL, Connolly SJ, Yusuf S, et al. Impact of Clopidogrel Therapy on Mortality and Cancer in Patients With Cardiovascular and Cerebrovascular Disease: A Patient-Level Meta-Analysis. Circ Cardiovasc Interv (2018) 11(1):e005795. doi: 10.1161/ CIRCINTERVENTIONS.117.005795

183. Serebruany VL, Cherepanov V, Cabrera-Fuentes HA, Kim MH. Solid Cancers After Antiplatelet Therapy: Confirmations, Controversies, and Challenges. Thromb Haemost (2015) 114(6):1104-12. doi: 10.1160/TH1501-0077

184. Serebruany VL, Tomek A, Kim MH. Survival After Solid Cancers in Antithrombotic Trials. Am J Cardiol (2015) 116(6):969-72. doi: 10.1016/ j.amjcard.2015.06.026

185. Turgeon RD, Koshman SL, Youngson E, Har B, Wilton SB, James MT, et al. Association of Ticagrelor vs Clopidogrel With Major Adverse Coronary Events in Patients With Acute Coronary Syndrome Undergoing Percutaneous Coronary Intervention. JAMA Intern Med (2020) 180 (3):420-8. doi: 10.1001/jamainternmed.2019.6447

186. Mammadova-Bach E, Gil-Pulido J, Sarukhanyan E, Burkard P, Shityakov S, Schonhart C, et al. Platelet Glycoprotein VI Promotes Metastasis Through Interaction With Cancer Cell-Derived Galectin-3. Blood (2020) 135 (14):1146-60. doi: 10.1182/blood.2019002649

187. Xiong Y, Liu L, Xia Y, Wang J, Xi W, Bai Q, et al. High CLEC-2 Expression Associates With Unfavorable Postoperative Prognosis of Patients With Clear 
Cell Renal Cell Carcinoma. Oncotarget (2016) 7(39):63661-8. doi: 10.18632/ oncotarget.11606

188. Volz J, Mammadova-Bach E, Gil-Pulido J, Nandigama R, Remer K, Sorokin L, et al. Inhibition of Platelet GPVI Induces Intratumor Hemorrhage and Increases Efficacy of Chemotherapy in Mice. Blood (2019) 133(25):2696-706. doi: 10.1182/blood.2018877043

189. Dovizio M, Maier TJ, Alberti S, Di Francesco L, Marcantoni E, Munch G, et al. Pharmacological Inhibition of Platelet-Tumor Cell Cross-Talk Prevents Platelet-Induced Overexpression of Cyclooxygenase-2 in HT29 Human Colon Carcinoma Cells. Mol Pharmacol (2013) 84(1):25-40. doi: 10.1124/ mol.113.084988

190. Ungerer M, Li Z, Baumgartner C, Goebel S, Vogelmann J, Holthoff HP, et al. The GPVI-Fc Fusion Protein Revacept Reduces Thrombus Formation and Improves Vascular Dysfunction in Atherosclerosis Without Any Impact on Bleeding Times. PloS One (2013) 8(8):e71193. doi: 10.1371/ journal.pone. 0071193

191. Ungerer M, Rosport K, Bultmann A, Piechatzek R, Uhland K, Schlieper P, et al. Novel Antiplatelet Drug Revacept (Dimeric Glycoprotein VI-Fc) Specifically and Efficiently Inhibited Collagen-Induced Platelet Aggregation Without Affecting General Hemostasis in Humans. Circulation (2011) 123 (17):1891-9. doi: 10.1161/CIRCULATIONAHA.110.980623

192. Kato Y, Kaneko MK, Kuno A, Uchiyama N, Amano K, Chiba Y, et al. Inhibition of Tumor Cell-Induced Platelet Aggregation Using a Novel AntiPodoplanin Antibody Reacting With its Platelet-Aggregation-Stimulating Domain. Biochem Biophys Res Commun (2006) 349(4):1301-7. doi: 10.1016/ j.bbrc.2006.08.171

193. Sekiguchi T, Takemoto A, Takagi S, Takatori K, Sato S, Takami M, et al. Targeting a Novel Domain in Podoplanin for Inhibiting Platelet-Mediated Tumor Metastasis. Oncotarget (2016) 7(4):3934-46. doi: 10.18632/ oncotarget.6598

194. Wang X, Liu B, Xu M, Jiang Y, Zhou J, Yang J, et al. Blocking Podoplanin Inhibits Platelet Activation and Decreases Cancer-Associated Venous Thrombosis. Thromb Res (2021) 200:72-80. doi: 10.1016/ j.thromres.2021.01.008

195. Chang YW, Hsieh PW, Chang YT, Lu MH, Huang TF, Chong KY, et al. Identification of a Novel Platelet Antagonist That Binds to CLEC-2 and Suppresses Podoplanin-Induced Platelet Aggregation and Cancer Metastasis. Oncotarget (2015) 6(40):42733-48. doi: 10.18632/oncotarget.5811

196. Tseng CP, Huang YL, Chang YW, Liao HR, Chen YL, Hsieh PW. Polysaccharide-Containing Fraction From Artemisia Argyi Inhibits Tumor Cell-Induced Platelet Aggregation by Blocking Interaction of Podoplanin With C-Type Lectin-Like Receptor 2. J Food Drug Anal (2020) 28(1):115-23. doi: 10.1016/j.jfda.2019.08.002

197. Damman P, Woudstra P, Kuijt WJ, de Winter RJ, James SK. P2Y12 Platelet Inhibition in Clinical Practice. J Thromb Thrombolysis (2012) 33(2):143-53. doi: 10.1007/s11239-011-0667-5

198. Zhao F, Li L, Guan L, Yang H, Wu C, Liu Y. Roles for GP IIb/IIIa and Alphavbeta3 Integrins in MDA-MB-231 Cell Invasion and Shear FlowInduced Cancer Cell Mechanotransduction. Cancer Lett (2014) 344(1):6273. doi: 10.1016/j.canlet.2013.10.019

199. McCarty OJ, Mousa SA, Bray PF, Konstantopoulos K. Immobilized Platelets Support Human Colon Carcinoma Cell Tethering, Rolling, and Firm
Adhesion Under Dynamic Flow Conditions. Blood (2000) 96(5):1789-97. doi: 10.1182/blood.V96.5.1789.h8001789_1789_1797

200. Zhang C, Liu Y, Gao Y, Shen J, Zheng S, Wei M, et al. Modified Heparins Inhibit Integrin Alpha(IIb)beta(3) Mediated Adhesion of Melanoma Cells to Platelets In Vitro and In Vivo. Int J Cancer (2009) 125(9):2058-65. doi: $10.1002 /$ ijc. 24561

201. Ballerini P, Dovizio M, Bruno A, Tacconelli S, Patrignani P. P2Y12 Receptors in Tumorigenesis and Metastasis. Front Pharmacol (2018) 9:66. doi: 10.3389/ fphar.2018.00066

202. Dutting S, Bender M, Nieswandt B. Platelet GPVI: A Target for Antithrombotic Therapy? Trends Pharmacol Sci (2012) 33(11):583-90. doi: 10.1016/j.tips.2012.07.004

203. Kato K, Kanaji T, Russell S, Kunicki TJ, Furihata K, Kanaji S, et al. The Contribution of Glycoprotein VI to Stable Platelet Adhesion and Thrombus Formation Illustrated by Targeted Gene Deletion. Blood (2003) 102(5):17017. doi: 10.1182/blood-2003-03-0717

204. Konstantinides S, Ware J, Marchese P, Almus-Jacobs F, Loskutoff DJ, Ruggeri ZM. Distinct Antithrombotic Consequences of Platelet Glycoprotein Ibalpha and VI Deficiency in a Mouse Model of Arterial Thrombosis. J Thromb Haemost (2006) 4(9):2014-21. doi: 10.1111/j.15387836.2006.02086.x

205. Jain S, Russell S, Ware J. Platelet Glycoprotein VI Facilitates Experimental Lung Metastasis in Syngenic Mouse Models. J Thromb Haemost (2009) 7 (10):1713-7. doi: 10.1111/j.1538-7836.2009.03559.x

206. Hughes CE, Navarro-Nunez L, Finney BA, Mourao-Sa D, Pollitt AY, Watson SP. CLEC-2 Is Not Required for Platelet Aggregation at Arteriolar Shear. J Thromb Haemost (2010) 8(10):2328-32. doi: 10.1111/j.1538-7836. 2010.04006.x

207. May F, Hagedorn I, Pleines I, Bender M, Vogtle T, Eble J, et al. CLEC-2 Is an Essential Platelet-Activating Receptor in Hemostasis and Thrombosis. Blood (2009) 114(16):3464-72. doi: 10.1182/blood-2009-05-222273

208. Saka-Herran C, Jane-Salas E, Mari-Roig A, Estrugo-Devesa A, Lopez-Lopez J. Time-to-Treatment in Oral Cancer: Causes and Implications for Survival. Cancers (Basel) (2021) 13(6):1321. doi: 10.3390/cancers13061321

Conflict of Interest: The authors declare that the research was conducted in the absence of any commercial or financial relationships that could be construed as a potential conflict of interest.

Publisher's Note: All claims expressed in this article are solely those of the authors and do not necessarily represent those of their affiliated organizations, or those of the publisher, the editors and the reviewers. Any product that may be evaluated in this article, or claim that may be made by its manufacturer, is not guaranteed or endorsed by the publisher.

Copyright $\odot 2021$ Hwang, Park, Cho, Zhang, Lee, Ahn, Chun, Chung and Song. This is an open-access article distributed under the terms of the Creative Commons Attribution License (CC BY). The use, distribution or reproduction in other forums is permitted, provided the original author(s) and the copyright owner(s) are credited and that the original publication in this journal is cited, in accordance with accepted academic practice. No use, distribution or reproduction is permitted which does not comply with these terms. 